\title{
Insight into Molecular Interactions of Two Methyl Benzoate Derivatives with Bovine Serum Albumin
}

\author{
Karolina Baranowska, Michał Mońka, Piotr Bojarski and Marek Józefowicz * $\mathbb{D}$
}

check for updates

Citation: Baranowska, K.; Mońka, M.; Bojarski, P.; Józefowicz, M. Insight into Molecular Interactions of Two Methyl Benzoate Derivatives with Bovine Serum Albumin. Int. J. Mol. Sci. 2021, 22, 11705. https://doi.org/ $10.3390 /$ ijms 222111705

Academic Editor: Andrea Pace

Received: 30 September 2021

Accepted: 26 October 2021

Published: 28 October 2021

Publisher's Note: MDPI stays neutral with regard to jurisdictional claims in published maps and institutional affiliations.

Copyright: (c) 2021 by the authors. Licensee MDPI, Basel, Switzerland This article is an open access article distributed under the terms and conditions of the Creative Commons Attribution (CC BY) license (https:/ / creativecommons.org/licenses/by/ $4.0 /)$
Institute of Experimental Physics, Faculty of Mathematics, Physics and Informatics, University of Gdańsk, Wita Stwosza 57, 80-308 Gdańsk, Poland; karolina.baranowska@phdstud.ug.edu.pl (K.B.); michal.monka@ug.edu.pl (M.M.); piotr.bojarski@ug.edu.pl (P.B.)

* Correspondence: marek.jozefowicz@ug.edu.pl

Abstract: The nature and mechanisms of interaction between two selected methyl benzoate derivatives (methyl $o$-methoxy $p$-methylaminobenzoate-I and methyl $o$-hydroxy $p$-methylaminobenzoateII) and model transport protein bovine serum albumin (BSA) was studied using steady-state and time-resolved spectroscopic techniques. In order to understand the role of Trp residue of BSA in the I-BSA and II-BSA interaction, the effect of free Trp amino acid on the both emission modes (LE-locally excited (I and II) and ESIPT-excited state intramolecular proton transfer (II)) was investigated as well. Experimental results show that the investigated interactions (with both BSA and Trp) are mostly conditioned by the ground and excited state complex formation processes. Both molecules form stable complexes with BSA and Trp (with 1:1 stoichiometry) in the ground and excited states. The binding constants were in the order of $10^{4} \mathrm{M}^{-1}$. The absorption- and fluorescence-titration experiments along with the time-resolved fluorescence measurements show that the binding of the I and II causes fluorescence quenching of BSA through the static mechanism, revealing a 1:1 interaction. The magnitude and the sign of the thermodynamic parameters, $\Delta H, \Delta S$, and $\Delta G$, determined from van't Hoff relationship, confirm the predominance of the hydrogen-bonding interactions for the binding phenomenon. To improve and complete knowledge of methyl benzoate derivative-protein interactions in relation to supramolecular solvation dynamics, the time-dependent fluorescence Stokes' shifts, represented by the normalized spectral response function $c(t)$, was studied. Our studies reveal that the solvation dynamics that occurs in subpicosecond time scale in neat solvents of different polarities is slowed down significantly when the organic molecule is transferred to BSA cavity.

Keywords: inclusion complex; bovine serum albumin; tryptophan; excited-state intramolecular proton transfer; supramolecular interactions

\section{Introduction}

During the past decade, considerable attention has been focused on characterization of noncovalent interactions between a macrocyclic host (chemical and/or biological) and different guest molecules (especially drugs and/or small bioactive molecules) [1-3] Cyclodextrins $(\alpha, \beta$ and $\gamma$ ), calixarenes, cucurbiturils, pillararenes, crown ethers and cyclophanes are one of such chemical organized assemblies possessing a hydrophobic nanocavity, which can accommodate guest molecules [4-6]. The understanding of the host-guest interactions is highly desirable for at least two main reasons. First, the explanation of the photochemical and photophysical processes leading to the formation of host-guest inclusion complex is interesting from a spectroscopic point of view, because the incorporation of the molecule into the chemical or biological nanocavity creates a new chemical system with significantly different spectroscopic properties [7,8]. Conversely, owing to complexation ability, chemical and biological cavities have received widespread attention for applications in medicine, agriculture, nanotechnology, cosmetics, food and pharmaceutical industries [9-14]. Among various representatives of chemical and biological macromolecules, nontoxic cyclodextrins (chemical) and human as well as bovine serum 
albumin (biological) are the most investigated ones because of their use in medicine as drug delivery carriers (cyclodextrins) and transport proteins (serum albumins) [15-19].

Serum albumins, the most abundant proteins in the blood plasma, play a significant role in the transport of both exogenous and endogenous compounds. Several experimental and theoretical studies have shown that human serum albumin (HSA) and bovine serum albumin (BSA) present an ideal model of serum carrier protein, and therefore they are most widely used as model proteins in evaluating small organic molecules (drug) - protein interactions [15,20-23]. BSA finds a wider range of applications because of its (i) low cost, (ii) high water solubility (iii) almost $80 \%$ sequence homology with HSA and (iv) widespread availability in a pure form. The crystal structure of BSA shows three domains (I, II, III), which are divided into two subdomains, named A and B [24,25] (Scheme 1A). The drugbinding sites are located in hydrophobic cavities in subdomains IIA and IIIA. Although HSA and BSA exhibit similar conformation properties, their spectroscopic properties are different. This is because BSA has two tryptophan residues that possess intrinsic fluorescence (Trp 134 and $\operatorname{Trp} 212$ ), whereas HSA has only one residue (Trp 214) [26,27]. Trp 212 is located within a hydrophobic binding pocket of the protein and Trp 134 is located on the surface of the molecule [24].
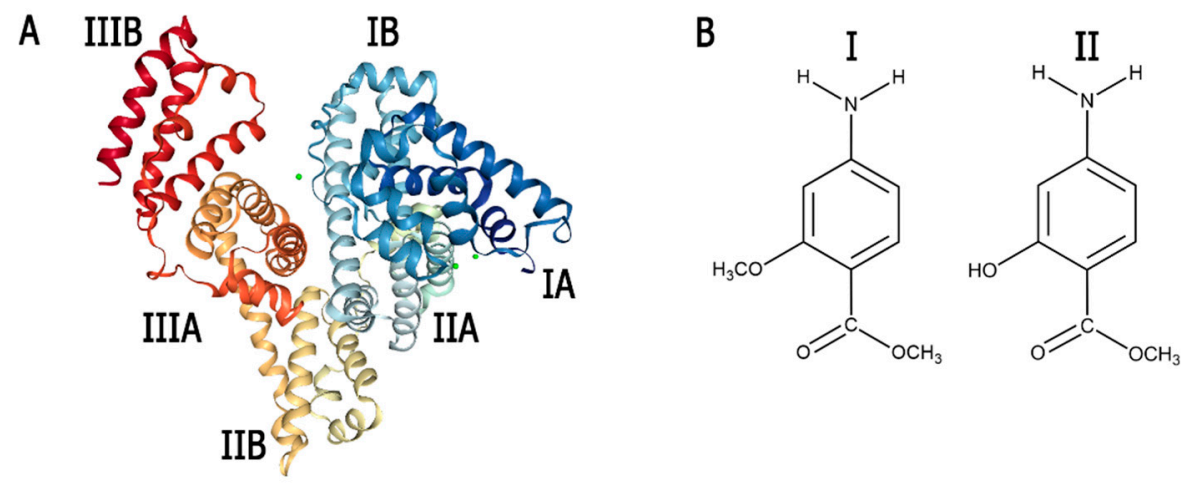

Scheme 1. Structure of bovine serum albumin (BSA) (A) and methyl benzoate derivatives (methyl $o$-methoxy $p$-methylaminobenzoate-I, methyl $o$-hydroxy $p$-methylaminobenzoate-II) (B).

We have recently undertaken spectroscopic investigations of the some methyl benzoate derivatives which, on the one hand, are interesting from the spectroscopic point of view (they are capable of exhibiting Twisted Intramolecular Charge Transfer- and/or Excited State Intramolecular Proton Transfer-type behaviour) and, conversely, they have potential in applications e.g., TICT and ESIPT fluorescence probes, metal ion sensors, active materials in dry xerographic toners or lasing medium in proton transfer lasers [28-32]. Our scientific attention has been focused not only on the description of the TICT and ESIPT processes of organic molecules in different organic solvents and heterogeneous systems, but also in aqueous solution in the presence of the supramolecular compounds $(\alpha-, \beta$ - and $\gamma$-cyclodextrins, cucurbit[7]uril) [33-37]. We have shown that photochemical and photophysical properties of investigated molecules encapsulated in macrocyclic host macrocyclic host are significantly different from those observed in bulk solution. These significant changes in spectroscopic behaviours were attributed to the formation of stable 1:1 and/or 1:2 inclusion complexes. The effect of macrocyclic host complexation on TICT and ESIPT photochemistry has been interpreted in terms of the protection of the embedded organic molecule in host cavity from the neighbouring water molecules (reduction of hydrogen bonds upon encapsulation), size and shape of macrocyclic host, orientation of the guest molecule in micropockets, restriction on molecular motion and the reduced polarity effect introduced by cavities as compared to the aqueous phase [33-37].

However, important issues on the nature and mechanisms of host guest interactions remain open and require clarification. Herein, we focus on the deepening the knowledge of the nature and mechanisms of interactions between two selected methyl 
benzoate derivatives (methyl $o$-methoxy $p$-methylaminobenzoate-I, methyl $o$-hydroxy $p$-methylaminobenzoate-II (Scheme 1B))-showing locally-excited (I and II) and ESIPT fluorescence (II)-and biological cavity (BSA). In particular, it is compared whether or not the investigated fluorophores show similar spectroscopic and photochemical properties in the presence of biological cavities (BSA) as in the case of chemical nanocages (cyclodextrins $(\alpha, \beta$ and $\gamma)$ and cucurbit[7]urils). The interaction of I and II with the model transport protein BSA is studied using steady-state and state-of-the-art time-resolved spectroscopic techniques, which proved to be helpful in understanding the mechanisms of the processes leading to the formation of a stable small organic molecule-protein complexes (quenching, binding and thermodynamic parameters). Overall, our current (in combination with our previous) studies offer a detailed outlook into the dynamic and structural aspects of chemical (CDs, cucurbit[7]urils) [33-37] and biological (BSA) host-guest interactions. Especially, we investigate the effects exerted by biological and chemical nanocavity on the excited-state intramolecular proton and electron transfer processes that may occur in supramolecular systems.

\section{Results and Discussion}

2.1. Steady-State Absorption and Fluorescence Spectra of I and II in the Phosphate Buffer in the Presence of $B S A$

As mentioned earlier, UV-visible absorption and fluorescence spectroscopy belongs to the most important techniques used to explore small organic molecule-protein interactions. This is due to the fact that the spectroscopic properties of HSA and/or BSA (in fact protein's fluorophores) are sensitive to the immediate neighbourhood i.e., polarity of their surroundings, as well as composition of the solvation shell. Thus, before undertaking the investigation of the interactions between BSA and two methyl benzoate derivatives (I and II), it is necessary to recall the spectroscopic behaviour of these two organic fluorophores, BSA, as well as three crucial amino acid residues: tryptophan (Trp), tyrosine (Tyr), and phenylalanine (Phe) (because, as mentioned, spectroscopic properties of the BSA are mainly governed by the absorption/fluorescence of above mentioned residues) [38].

Several spectroscopic investigations were carried out on the I-BSA and II-BSA systems (and in parallel on the I-Trp, II-Trp systems) to recognize whether some interactions occurred and to obtain insight into the nature of such interactions. The spectral characteristics of the two investigated methyl benzoate derivatives, BSA and three crucial amino acid residues (Trp, Tyr, Phe) in the phosphate buffer are presented in Figure 1. As can be seen, these residues have distinct absorption and emission wavelengths and differ in the quantum yield (in aqueous medium quantum yields of Trp, Tyr and Phe are near 0.2, 0.14 and 0.03 , respectively) [38]. Several experimental and theoretical studies have shown that, proteins emission is dominated by Trp, which absorbs at the longest wavelength $\left(\lambda_{\max }^{a b s}(\operatorname{Tr} p)\right.$ in phosphate buffer occurs at $\left.280 \mathrm{~nm}\right)$ and displays the largest molar absorption coefficient [38]. Although Tyr quantum yield is similar to that of Trp, emission is often quenched, mostly due to its interactions with the peptide chain or as a result of energy transfer to Trp [38]. As can be seen, Tyr can be excited at wavelengths similar to that of $\operatorname{Trp}\left(\left(\lambda_{\max }^{a b s}(\mathrm{Tyr})\right.\right.$ in phosphate buffer occurs at $\left.275 \mathrm{~nm}\right)$ but emits at a distinctly different wavelength. The wavelength of maximum intensity of the fluorescence band of Tyr is distinctly blue-shifted in comparison to the fluorescence band of $\operatorname{Trp}\left(\lambda_{\max }^{f l}(\mathrm{Tyr})=303 \mathrm{~nm}\right.$, $\left.\lambda_{\max }^{f l}(\operatorname{Trp})=351 \mathrm{~nm}\right)$. It is also evident that among the three crucial amino acids, Phe displays the shortest absorption and emission wavelengths. Considering that proteins fluorescence is generally excited at $280 \mathrm{~nm}$ or at longer wavelengths, Phe is not excited in the majority of experiments (this holds true also in our case). 


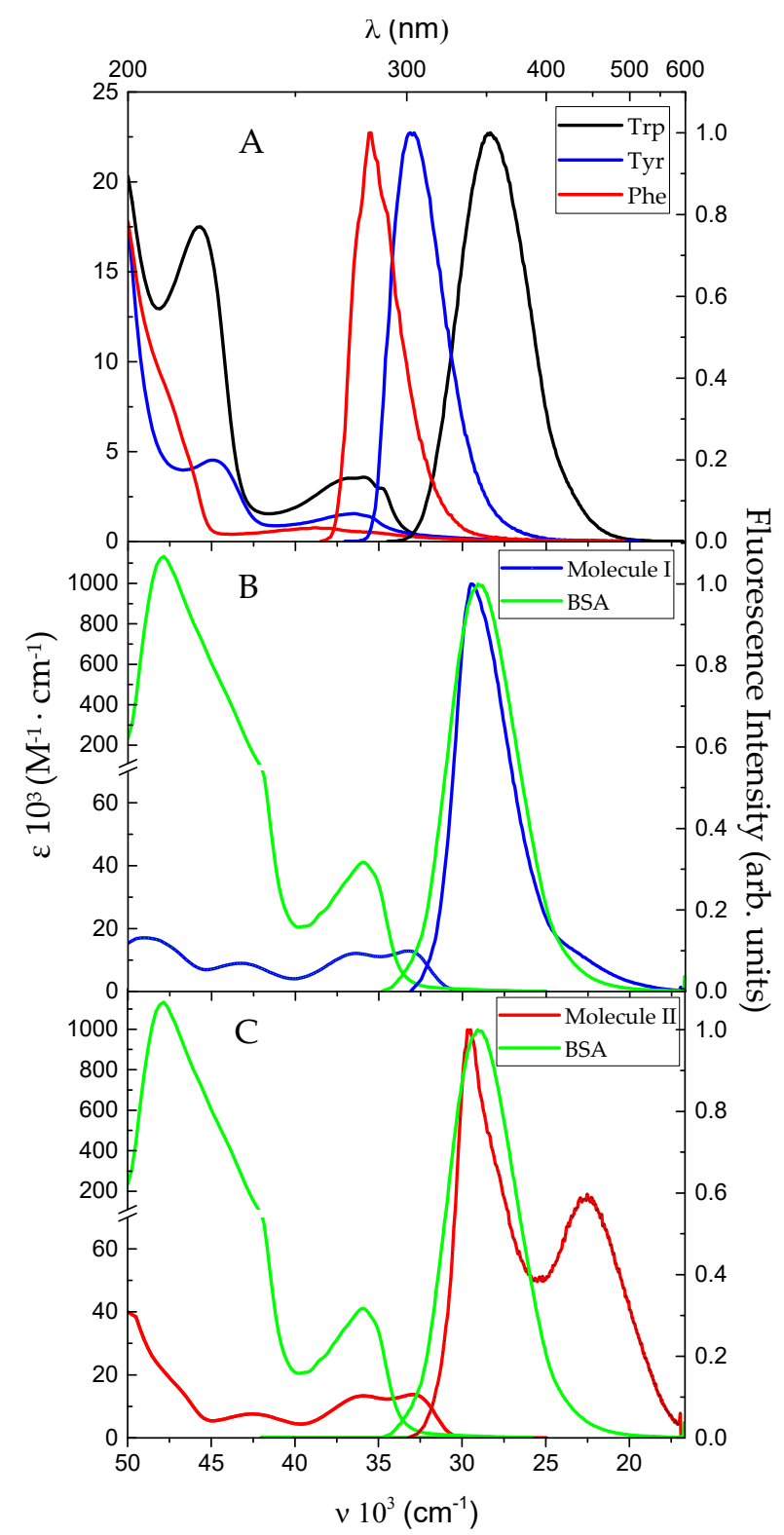

Figure 1. Absorption and emission spectra of the three crucial aromatic amino acids (A), BSA (B,C) and investigated dyes $(\mathbf{B}, \mathbf{C})$ in phosphate buffer solution ( $\mathrm{pH}$ 7.4). In order to better visualize the absorbance scale (representing the molar absorption coefficient) for BSA and investigated molecules, the ordinate axis has been truncated.

In previous reports [28-32], we have shown that the long-wavelength absorption band of the studied fluorophores in neat solvents consists of two electronic transitions $S_{0} \rightarrow S_{1}$ and $S_{0} \rightarrow S_{2}$ of different character: $\pi \pi^{*}$ and charge-transfer (CT). Moreover, it is well established that molecule II dissolved in some media besides the locally-excited (LE) fluorescence exhibits the long-wavelength emission from the excited-state intramolecular proton transfer (ESIPT) state [28-32]. In Figure 1B,C, the long-wavelength absorption and fluorescence spectra of BSA in the phosphate buffer are compared with those of I and II. As the spectral behaviours of BSA mainly arise due to the presence of two tryptophan residues (Trp-212 (located in hydrophobic subdomain IB) and Trp-134 (located near the surface of the albumin molecule in the second helix of the first domain)), the steady-state absorption and fluorescence spectra of BSA and Trp show similar spectral features $\left(\lambda_{\max }^{a b s}(\operatorname{Trp})=280 \mathrm{~nm}\right.$ versus $\lambda_{\max }^{a b s}(\mathrm{BSA})=278 \mathrm{~nm}, \lambda_{\max }^{f l}(\operatorname{Trp})=351 \mathrm{~nm}$ versus 
$\left.\lambda_{\max }^{f l}(\mathrm{BSA})=344 \mathrm{~nm}\right)$. The long-wavelength absorption spectrum of BSA overlaps with the broad, long-wavelength absorption band (consisting of two different electronic transitions) of the investigated methyl benzoate derivatives, as well as the short-wavelength, locallyexcited fluorescence band of I and II considerably overlap with that of serum protein.

In order to obtain more insight into I-BSA and II-BSA interaction process, the absorptionand fluorescence-titration experiments were performed with varying concentrations of BSA. Figure 2 shows the LW absorption spectra of I and II in the phosphate buffer solutions containing different concentrations of BSA. Upon addition of BSA, the molar absorption coefficient of the first long-wavelength absorption band centred at about $275 \mathrm{~nm}$ (molecule I) and $279 \mathrm{~nm}$ (molecule II) gradually increases, whereas no significant changes in the second long-wavelength absorption band (centred at $300 \mathrm{~nm}$ (I) and $305 \mathrm{~nm}$ (II)) were observed in the presence of BSA. Considering the absorption characteristics of BSA in phosphate buffer solution, this spectral behaviour probably comes from the absorption of BSA molecule. Moreover, an isosbestic point can be clearly seen between these two bands, which indicates the presence of equilibrium between two different species (I (or II) and the ground-state complex I-BSA (or II-BSA)).

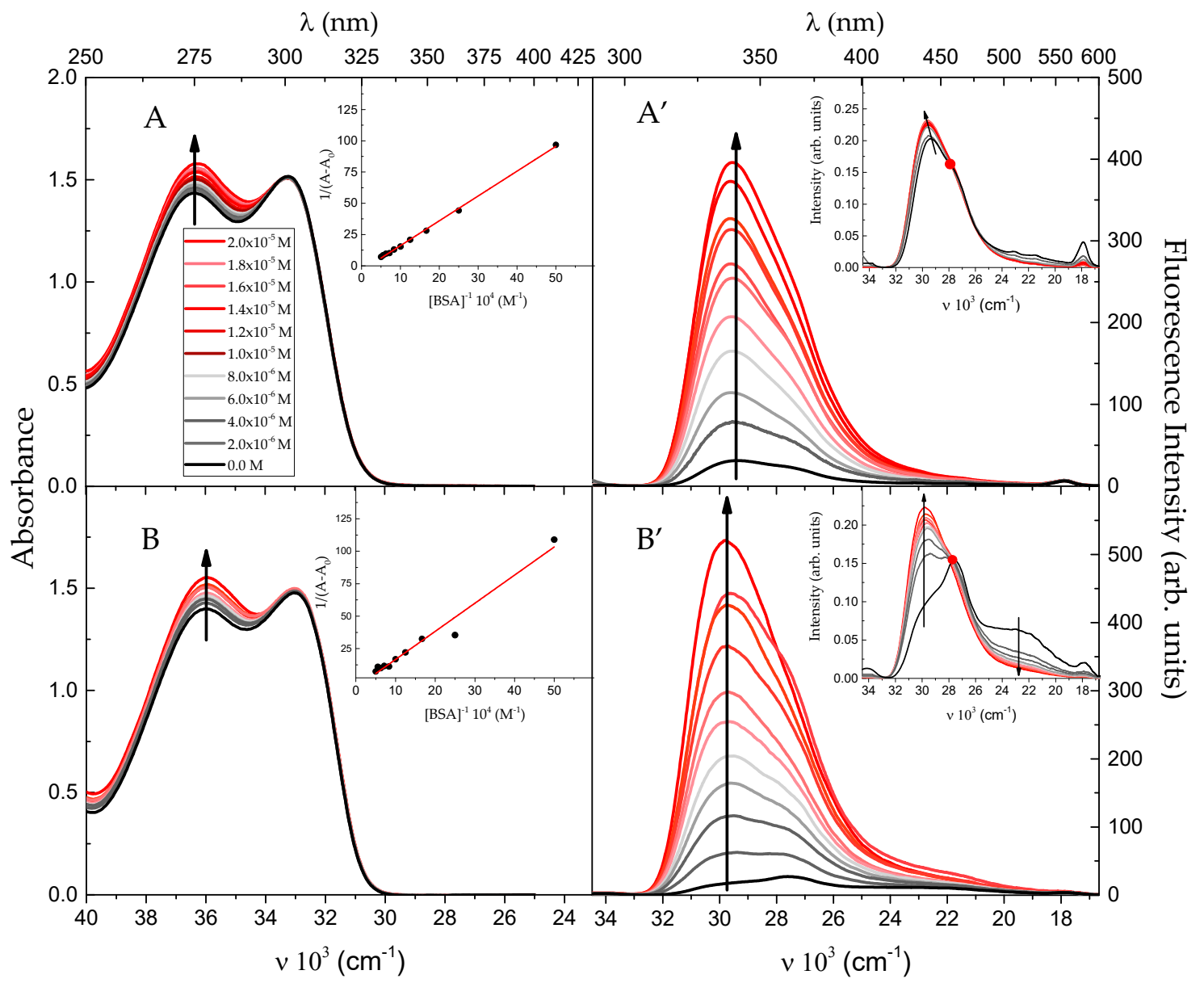

Figure 2. Absorption and fluorescence spectra $\left(\lambda_{\text {exc. }}=300 \mathrm{~nm}\right)$ of $\mathbf{I}\left(\mathbf{A}, \mathbf{A}^{\prime}\right), \mathbf{I I}\left(\mathbf{B}, \mathbf{B}^{\prime}\right)\left(\mathrm{c}=5 \times 10^{-5} \mathrm{M}\right)$ in phosphate buffer solutions containing different concentration of BSA $\left(0 \mathrm{M}, 2.0 \times 10^{-6} \mathrm{M}, 4.0 \times 10^{-6} \mathrm{M}, 6.0 \times 10^{-6} \mathrm{M}, 8.0 \times 10^{-6} \mathrm{M}, 1.0 \times 10^{-5} \mathrm{M}\right.$, $\left.1.2 \times 10^{-5} \mathrm{M}, 1.4 \times 10^{-5} \mathrm{M}, 1.6 \times 10^{-5} \mathrm{M}, 1.8 \times 10^{-5} \mathrm{M}, 2.0 \times 10^{-5} \mathrm{M}\right)$. Insert the ground-state Benesi-Hildebrand dependence for I (A), II (B) and the normalized fluorescence spectra of $\mathbf{I}\left(\mathbf{A}^{\prime}\right)$ and II (B') in phosphate buffer solutions containing different concentration of BSA.

Addition of BSA to the phosphate buffer solutions of I and II brings about a strong increase in the fluorescence intensity with a slight shift in the position of the short-wavelength fluorescence band maximum $(\sim 4 \mathrm{~nm})$. Moreover, when the protein concentration is in- 
creased, an isosbestic point can be clearly seen in normalized fluorescence spectra (we normalized each of the area under the fluorescence curve to unity, in this case, fluorescence spectrum corresponds to the emission of the same number of emitting molecules) points that equilibrium is established also in the excited state for both studied systems (see insert of Figure 2). The appearance of an isosbestic point-like feature in the normalized fluorescence spectra of molecule which is capable of exhibiting ESIPT-type behaviour (molecule II) and gradual decrease in the intensity of the ESIPT fluorescence band indicate that the binding between II and BSA is specific and involves the hydroxy $(-\mathrm{OH})$ and /or ester $\left(-\mathrm{COOCH}_{3}\right)$ groups, which causes that ESIPT does not appear.

The changes in the absorbance and fluorescence intensity of I and II in the presence of BSA have been used to create the Benesi-Hildebrand $(B-H)$ plot (see Equation $(2 a, b)$ ). As can be seen in the insert of Figure 2 and Figure S1 (Supplementary Materials), for both investigated systems, the plots of $1 /\left(A-A_{0}\right)$ versus $1 /[\mathrm{BSA}]$, as well as $1 /\left(I-I_{0}\right)$ versus $1 /[\mathrm{BSA}])$ demonstrate linear dependence, which indicates the formation of well-defined 1:1 complexes with BSA, both in the ground and excited states. The binding constants were found to be $(1.9 \pm 0.1) \times 10^{4} \mathrm{M}^{-1}$ and $(2.3 \pm 0.1) \times 10^{4} \mathrm{M}^{-1}$ in the ground state and $(2.1 \pm 0.1) \times 10^{4} \mathrm{M}^{-1}$ and $(2.0 \pm 0.1) \times 10^{4} \mathrm{M}^{-1}$ in the excited state for $\mathbf{I}$ and II, respectively. These results indicate the strong binding affinity of the investigated dyes to BSA in the ground and excited states.

\subsection{Time-Resolved Studies of I and II in the Phosphate Buffer in the Presence of BSA}

To obtain information on the excited-state dynamics of the methyl benzoate derivativeBSA system in the phosphate buffer, the time-resolved emission spectra (TRES) of the investigated dyes upon the gradual addition of BSA were recorded. Table 1 gives the fluorescence lifetimes and preexponential factors describing the contribution of the i-th fluorescence decay component to the total emission.

Table 1. Fluorescence lifetimes of I and II in phosphate buffer solutions containing different concentrations of BSA.

\begin{tabular}{|c|c|c|c|c|c|c|c|c|}
\hline Molecule & BSA Concentration $10^{-5}(\mathrm{M})$ & $\tau_{1}(\mathrm{~ns})$ & $A_{1}(\%)$ & $\tau_{2}(\mathrm{~ns})$ & $A_{2}(\%)$ & $\tau_{3}(\mathrm{~ns})$ & $A_{3}(\%)$ & $\mathbf{r}^{2}$ \\
\hline \multirow{8}{*}{ I } & 0 & 0.19 & 100 & & & & & 0.98 \\
\hline & 0.1 & 0.20 & 7 & & & 4.49 & 93 & 0.99 \\
\hline & 0.2 & 0.30 & 3 & & & 5.36 & 97 & 0.99 \\
\hline & 0.4 & 0.30 & 2 & & & 5.18 & 98 & 0.99 \\
\hline & 0.6 & 0.32 & 1 & & & 5.57 & 99 & 0.99 \\
\hline & 0.8 & & & & & 5.51 & 100 & 0.99 \\
\hline & 1.4 & & & & & 5.69 & 100 & 0.99 \\
\hline & 2.0 & & & & & 5.78 & 100 & 0.99 \\
\hline \multirow{8}{*}{ II } & 0 & 0.20 & 24 & 0.80 & 76 & & & 0.95 \\
\hline & 0.1 & 0.21 & 14 & 1.15 & 15 & 5.79 & 71 & 0.99 \\
\hline & 0.2 & 0.19 & 5 & 1.19 & 17 & 5.56 & 78 & 0.99 \\
\hline & 0.4 & 0.19 & 2 & 1.00 & 9 & 5.71 & 89 & 0.99 \\
\hline & 0.6 & 0.18 & 1 & 1.00 & 6 & 5.23 & 93 & 0.99 \\
\hline & 0.8 & & & & & 5.58 & 100 & 0.99 \\
\hline & 1.4 & & & & & 5.52 & 100 & 0.99 \\
\hline & 2.0 & & & & & 5.84 & 100 & 0.99 \\
\hline
\end{tabular}

We will first discuss the changes in the fluorescence lifetimes of molecule II, which is capable of exhibiting ESIPT-type behaviour, in the presence of BSA in the phosphate buffer medium. As expected, fluorescence decay profile of II recorded in the absence of BSA 
consists of a slow decay $\tau_{2}=0.8 \mathrm{~ns}$ as a major component (76\%) with a small contribution of a fast decay component $\left(\tau_{1}=200 \mathrm{ps}, A_{1}=24 \%\right)$. According to our previous works [35,37], we can state that the slow component can be assigned to the emission from ESIPT state, whereas the decay time of the fast component originates from the emission of LE state.

The fluorescence kinetics of II in the presence of BSA are of the most complex nature (see Table 1 and Figure 3). In the presence of BSA at low concentration $\left(10^{-6}-6 \times 10^{-6} \mathrm{M}\right)$, the decay fits to three-exponential function with time constants of $\tau_{1} \sim 200 \mathrm{ps}, \tau_{2} \sim 1 \mathrm{~ns}$ and $\tau_{3} \sim 5.7 \mathrm{~ns}$, whereas at the highest concentration $\left(8 \times 10^{-6}-2 \times 10^{-5} \mathrm{M}\right)$, fluorescence decays can be reasonably well fitted by monoexponential function $\left(\tau_{3} \sim 5.7 \mathrm{~ns}\right)$ (see Table 1 and Figure 3). Through the individual form of the time constants of II (LE and ESIPT) remain almost unchanged, their relative preexponential factors are distinctly modified upon interactions with BSA. The preexponential factors associated with the LE an ESIPT emission $\left(A_{1}\right.$ and $A_{2}$ ) are found to be decreased from $24 \%$ and $76 \%$ to $1 \%$ and $6 \%$, respectively, whereas $A_{3}$ factor presents opposite behaviour. These results clearly indicate that the short components $\left(\tau_{1}\right.$ and $\left.\tau_{2}\right)$ correspond to the unbound forms (LE and ESIPT), while the long component $\tau_{3}$ corresponds to the bound form (II-BSA). Moreover, this binding results in the absence of the intramolecular proton transfer process in the excited state, confirming the involvement of the hydroxy $(-\mathrm{OH})$ and/or ester $\left(-\mathrm{COOCH}_{3}\right)$ groups in specific interactions.

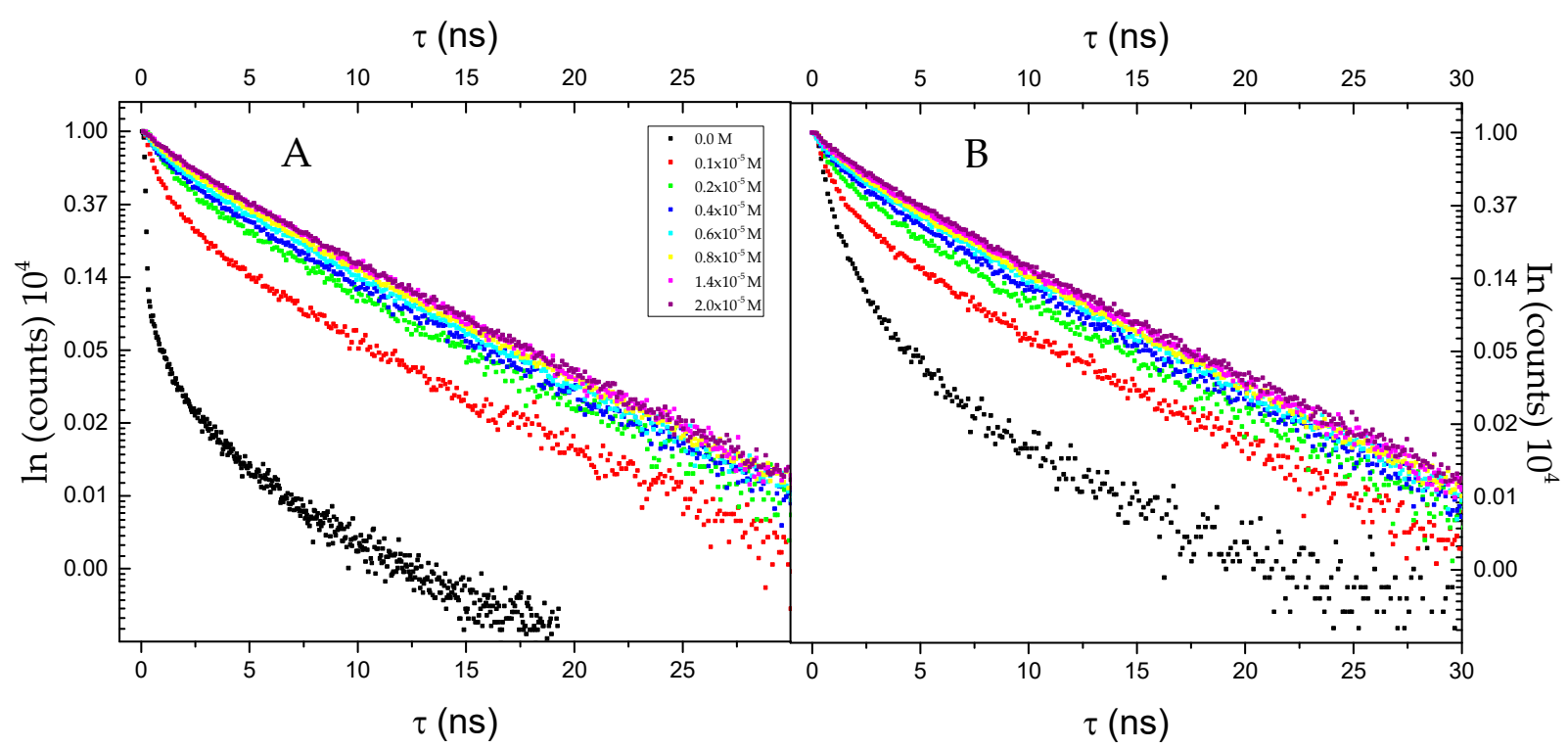

Figure 3. Fluorescence decay profiles of $\mathbf{I}(\mathbf{A})$ and $\mathbf{I I}(\mathbf{B})$ in absence and different concentration of BSA $\left(0.0 \mathrm{M}, 0.1 \times 10^{-5} \mathrm{M}\right.$, $\left.0.2 \times 10^{-5} \mathrm{M}, 0.4 \times 10^{-5} \mathrm{M}, 0.6 \times 10^{-5} \mathrm{M}, 0.8 \times 10^{-5} \mathrm{M}, 1.4 \times 10^{-5} \mathrm{M}, 2.0 \times 10^{-5} \mathrm{M}\right)$.

For the molecule I in the phosphate buffer medium, the fluorescence decay profile can be satisfactorily fitted by monoexponential function with the fluorescence decay time $\tau_{1} \sim 200 \mathrm{ps}$ (Table 1), in the presence of BSA at low concentration $\left(10^{-6}-6 \times 10^{-6} \mathrm{M}\right)$, the sum of two exponential functions was required, whereas at the highest concentration $\left(8 \times 10^{-6}-2 \times 10^{-5} \mathrm{M}\right)$, again only one emissive centre was observed ( $\left.\tau_{3} \sim 5.7 \mathrm{~ns}\right)$ (Figure 3). In the presence of low concentration of BSA $\left(10^{-6} \mathrm{M}\right)$, fluorescence kinetics exhibits a slow decay component $\tau_{3}$ as a major component (93\%), which is close to the average lifetime of two Trp moieties [21], with a small contribution of fast decay component ( $\tau_{1} \sim 200 \mathrm{ps}$ ). It should be also clearly state that, the values of fast and slow decay components ( $\tau_{1}$ and $\tau_{3}$ ) remain almost unchanged ( $\tau_{1}$ slightly increases) with increasing BSA concentration. Conversely, the preexponential factor $A_{1}$ corresponding to the decay of LE form of the molecule I decreases with increasing BSA concentration, whereas $A_{3}$ factor presents opposite behaviour. These findings indicate that the possibility of the emission from LE state 
is limited due to the presence of specific interactions between I and BSA (formation of I-BSA complex).

In our previous paper, the mechanism of supramolecular solvation dynamics of the methyl benzoate derivatives in aqueous solution with $\mathrm{CB}$ [7] has been investigated according to the procedure described by Maroncelli and Fleming [37,39,40]. We have shown that solvation dynamics which occurs in subpicosecond time scale in neat solvents of different polarities is slowed down significantly when organic molecule is relocated to $\mathrm{CB}$ [7] cavity. In order to determine and compare solvation dynamics in selected chemical and biological nanocavities (i.e., $\mathrm{CB}[7]$ ) versus BSA), the time-dependent fluorescence Stokes' shifts (determined from the emission spectra registered at various times after excitation (see Figure 4), were used to create the normalized solvation correlation function $c(t)$ (see Equation (7)). Figure 5 presents the temporal behaviour of $c(t)$ function for I and II bound to BSA. For both molecules, decay of $c(t)$ is well fitted by the sum of two exponential functions (see Equation (8)) with a fast component $\tau_{1 \text { (solv.) }}(\mathbf{I})=430 \mathrm{ps}, \tau_{1 \text { (solv.) }}($ III) $=520 \mathrm{ps}$ $\left(A_{1 \text { (solv.) }}(\mathbf{I})=2 \%, A_{1 \text { (solv.) }}(\mathbf{I I})=3 \%\right)$ and a slow component of $\tau_{2 \text { (solv.) }}(\mathbf{I})=4.07 \mathrm{~ns}, \tau_{2 \text { (solv. })}$ (II) $=5.25 \mathrm{~ns}\left(A_{1 \text { (solv.) }}(\mathbf{I})=98 \%, A_{1 \text { (solv.) }}(\right.$ II $\left.)=97 \%\right)$, with an average solvation time $\left\langle\tau_{\text {(solv. })}\right.$ $(\mathrm{I})\rangle=4.06 \mathrm{~ns}$, and $\left\langle\tau_{(\text {solv. })}(\mathrm{II})\right\rangle=5.24 \mathrm{~ns}$.

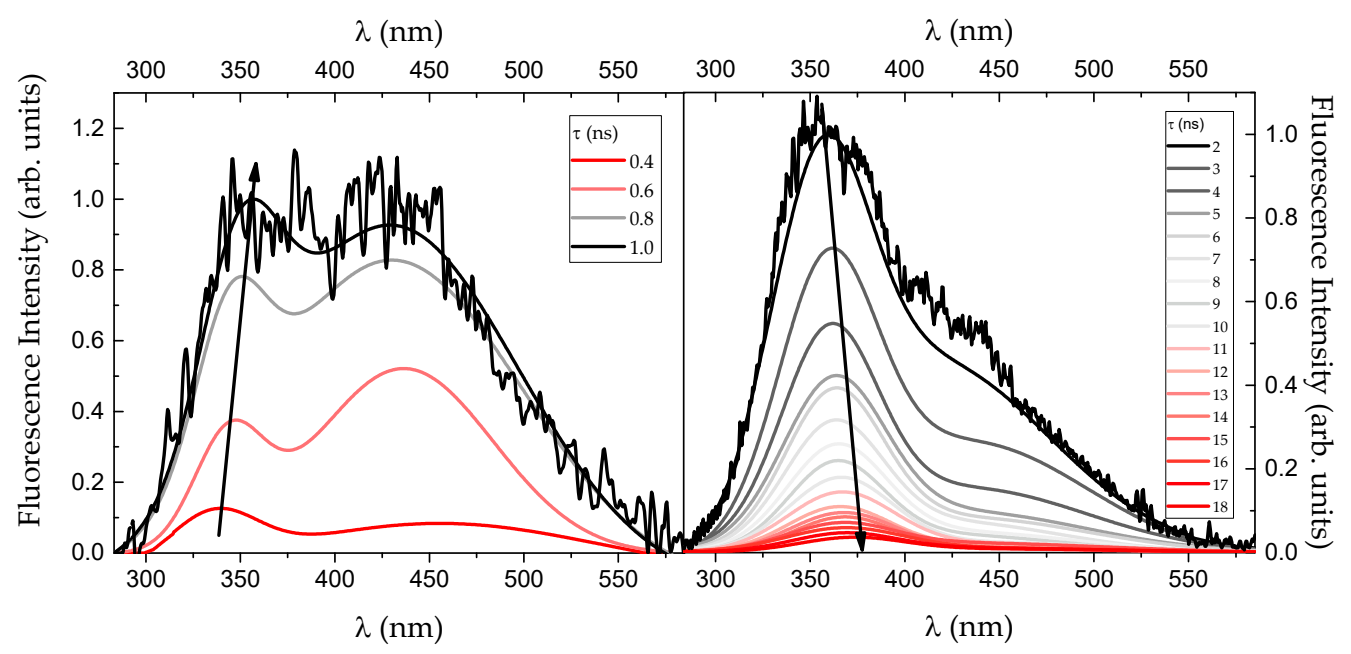

Figure 4. Time-resolved emission spectra $\left(\lambda_{\text {exc. }}=300 \mathrm{~nm}\right)$ of II in phosphate buffer solution with BSA $\left(\mathrm{c}_{\mathrm{BSA}}=10^{-6} \mathrm{M}\right)$ at various times after excitation.

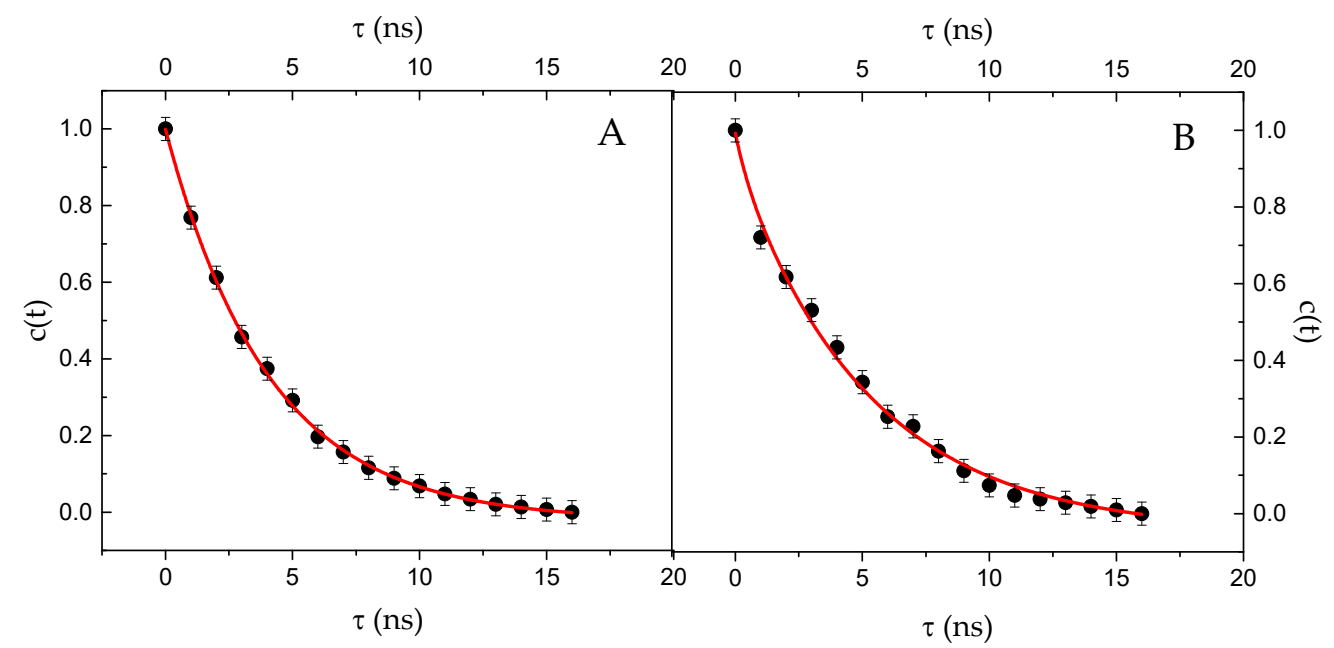

Figure 5. Temporal behaviour of $c(t)$ function for the short-wavelength fluorescence band of I (A) and II (B) in phosphate buffer solution with BSA $\left(c_{B S A}=10^{-6} \mathrm{M}\right)$. 
In order to explain the presence of the nanosecond component of the solvation dynamics observed in our studies, it is necessary to assume the restriction on the movement of the biological water molecules in the vicinity of the protein. Similar behaviour has been reported previously and explained as a result of three main causes: (i) in bulk, the movement of water is cooperative and involves an extensive network of hydrogen bonds, (ii) in the case of protein-bound water, the hydrogen bond network is significantly disturbed, (iii) the different solvation times of biological water molecules may correspond to different parts of albumin [41,42]. Thus, the present investigation clearly shows that the solvation dynamics of I and II in aqueous solution with CB[7] is different from that in biological nanocavities (BSA). The average solvation time in methyl benzoate derivative-BSA system is found to be about one order of magnitude longer than that in I-CB[7] (or II-CB[7]) system. This indicates that at BSA hydrophobic interior, where investigated organic molecule is buried, the water molecules are more strongly confined than in the CB[7] cavity and therefore show slower solvation dynamics.

\subsection{Effect of Trp on the Steady-State and Time-Resolved Spectroscopic Behaviour of I and II}

In order to understand the role of Trp residue of BSA in the I-BSA and II-BSA interaction, it is useful to also study the interactions between molecules under study and the free Trp amino acid. As seen in Figure 6, the steady-state absorption and fluorescence spectra of buffered solutions of I and II are also affected by the presence of tryptophan molecules. For both fluorophores, with the gradual addition of Trp, the molar absorption coefficient of the first long-wavelength absorption band increases without change in spectral distribution of the second LW absorption band. Moreover, the occurrence of an isosbestic point in the titration experiment suggests that the equilibrium is established between methyl benzoate derivative (I or II) and the methyl benzoate derivative-Trp complex in the ground state. The excited-state spectral behaviours of I-Trp and II-Trp systems (e.g., increase in the fluorescence intensity and presence of an isosbestic point in the steady-state area normalized emission spectra) are similar to those in I-BSA and II-BSA systems suggesting that methyl benzoate derivative-Trp complex is also formed in the excited state. It is also evident from the normalized fluorescence spectra that for fluorophore II, upon increasing the Trp concentration, the intensity of the ESIPT fluorescence band decreases and simultaneously the short-wavelength (LE) emission band increases. The described experiment indicates (as was the case with II-BSA system) the involvement of the -OH and/or - $\mathrm{COOCH}_{3}$ ) substituents in specific interactions between II and Trp. Here, the same absorption- and fluorescence-titration experiments were performed for I-Tyr, II-Tyr, I-Phe and II-Phe systems. For these systems, the absorption and fluorescence spectra of I and II in phosphate buffer solution containing different concentration of two amino acid residues (Tyr and Phe) were practically unchanged, which indicates that probably no specific interaction with Tyr and Phe occurs.

As can be seen in Figure $\mathrm{S} 2$, for both studied systems, the plots of $1 /\left(A-A_{0}\right)$ versus $1 /[\operatorname{Trp}]$ and $1 /\left(I-I_{0}\right)$ versus $1 /[$ Tryp] show linear dependence over the whole range of studied Trp concentration, confirming the formation of complexes with 1:1 stoichiometry between methyl benzoate derivatives (I and II) and Trp in the ground and excited states. The binding constants were found to be $(2.1 \pm 0.1) \times 10^{4} \mathrm{M}^{-1}$ and $(2.6 \pm 0.1) \times 10^{4} \mathrm{M}^{-1}$ in the ground state and $(1.9 \pm 0.1) \times 10^{4} \mathrm{M}^{-1}$ and $(2.6 \pm 0.1) \times 10^{4} \mathrm{M}^{-1}$ in the excited state for I and II, respectively, which is similar to the previously calculated values for I-BSA and II-BSA complexes. This behaviour may indicate that mainly the Trp residue of BSA is involved in process of I-BSA and II-BSA specific interactions.

As can be seen in Table 2, the fluorescence kinetics of the investigated molecules in the presence of Trp is similar to that in I-BSA and II-BSA systems ((i) decay components $\left(\tau_{1}, \tau_{2}\right.$ and $\tau_{3}$ ) remain almost unchanged; (ii) the preexponential factors $A_{1}$ and $A_{2}$ corresponding to decay of LE and ESIPT (molecule II) emission decrease with increasing Trp concentration, whereas $A_{3}$ factor (corresponding to the decay of bound form (I-Trp and II-Trp)) presents opposite behaviour) confirming the formation of complex between methyl benzoate derivatives (I and II) and Trp. 


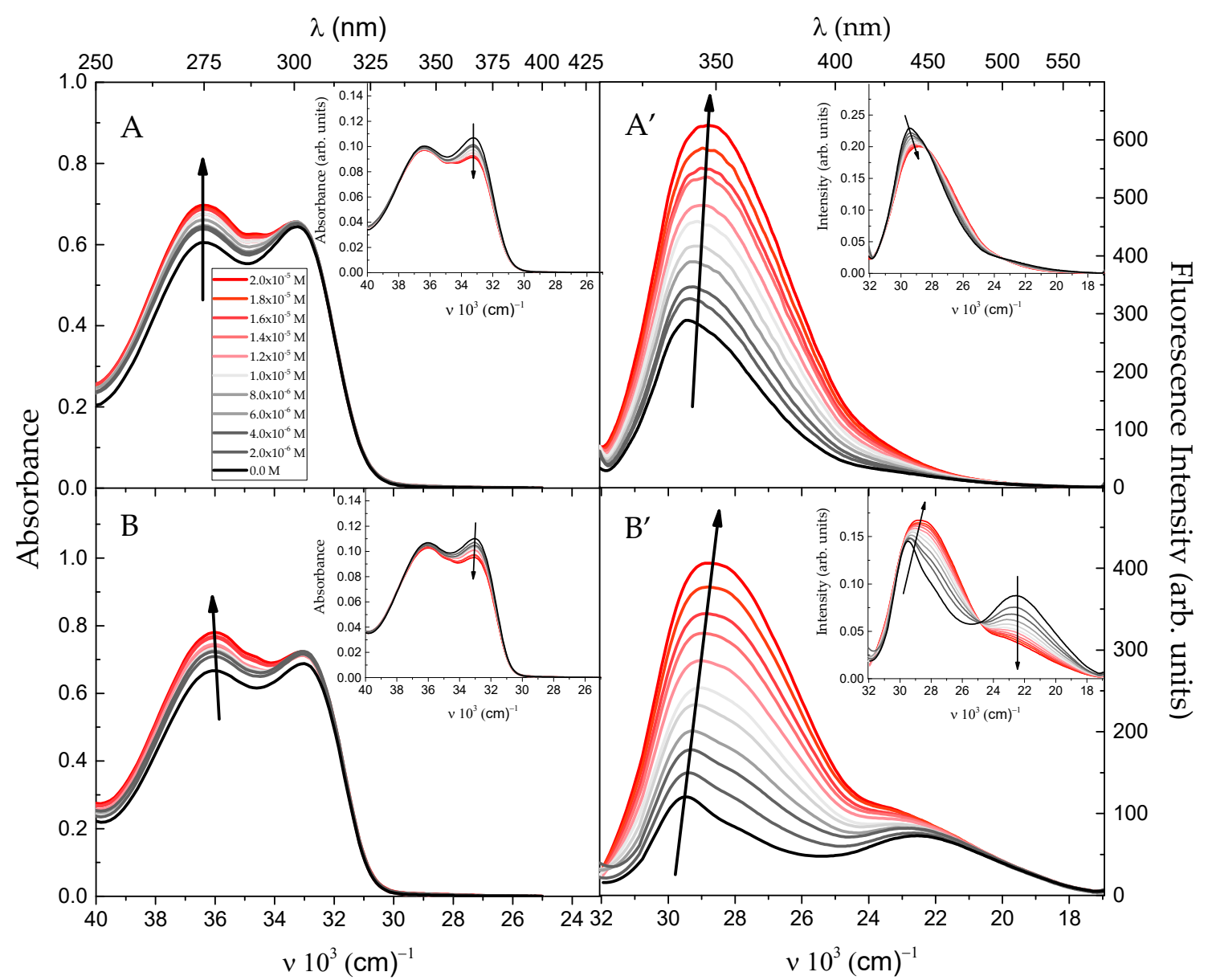

Figure 6. The long-wavelength absorption and fluorescence spectra $\left(\lambda_{\text {exc. }}=300 \mathrm{~nm}\right)$ of $\mathbf{I}\left(\mathbf{A}, \mathbf{A}^{\prime}\right)$ and $\mathbf{I I}\left(\mathbf{B}, \mathbf{B}^{\prime}\right)\left(\mathbf{c}=5 \times 10^{-5} \mathrm{M}\right)$ in phosphate buffer solutions containing different concentration of $\operatorname{Trp}\left(0 \mathrm{M}, 2.0 \times 10^{-6} \mathrm{M}, 4.0 \times 10^{-6} \mathrm{M}, 6.0 \times 10^{-6} \mathrm{M}\right.$, $\left.8.0 \times 10^{-6} \mathrm{M}, 1.0 \times 10^{-5} \mathrm{M}, 1.2 \times 10^{-5} \mathrm{M}, 1.4 \times 10^{-5} \mathrm{M}, 1.6 \times 10^{-5} \mathrm{M}, 1.8 \times 10^{-5} \mathrm{M}, 2.0 \times 10^{-5} \mathrm{M}\right)$. In order to better visualize the changes in the absorption (in the long-wavelength (LW) region) and emission spectra, the normalized spectra (by scaling the area under the spectrum to be equal to unity) are presented in insert.

Table 2. Fluorescence lifetimes of I and II in phosphate buffer solutions containing different concentration of Trp.

\begin{tabular}{|c|c|c|c|c|c|c|c|c|}
\hline Molecule & Trp Concentration $10^{-5}(\mathrm{M})$ & $\tau_{1}(\mathrm{~ns})$ & $A_{1}(\%)$ & $\tau_{2}(\mathrm{~ns})$ & $A_{2}(\%)$ & $\tau_{3}$ (ns) & $A_{3}(\%)$ & $\mathbf{r}^{2}$ \\
\hline \multirow{6}{*}{ I } & 0 & 0.19 & 100 & & & & & 0.97 \\
\hline & 0.4 & 0.14 & 12 & & & 3.45 & 88 & 0.99 \\
\hline & 0.8 & 0.12 & 6 & & & 3.34 & 94 & 0.99 \\
\hline & 1.2 & 0.12 & 5 & & & 3.5 & 95 & 0.99 \\
\hline & 1.6 & 0.13 & 3 & & & 3.5 & 97 & 0.99 \\
\hline & 2.0 & 0.14 & 2 & & & 3.5 & 98 & 0.99 \\
\hline \multirow{6}{*}{ II } & 0 & 0.20 & 24 & 0.80 & 76 & & & 0.95 \\
\hline & 0.4 & 0.13 & 4 & 0.65 & 15 & 3.46 & 81 & 0.98 \\
\hline & 0.8 & 0.11 & 3 & 0.87 & 7 & 3.71 & 90 & 0.99 \\
\hline & 1.2 & 0.16 & 1 & 0.61 & 3 & 3.49 & 96 & 0.96 \\
\hline & 1.6 & & & & & 2.90 & 100 & 0.98 \\
\hline & 2.0 & & & & & 2.98 & 100 & 0.98 \\
\hline
\end{tabular}


The presented above findings suggest that mainly Trp residue of BSA is involved in the process of specific interaction between I (or II) and BSA. Considering possible location of Trp in BSA, it can be concluded that the molecules I and II enter the hydrophobic cleft of the IB subdomain (location of the Trp-212 molecule) or near the surface of the albumin molecule in the second helix of the first domain (location of the Trp-134 molecule) and form specific hydrogen bonds with Trp-212 and/or Trp-134, thereby causing static fluorescence quenching of BSA (Trp). Moreover, as the investigated fluorophores have the chemically active substituents which are likely sites for intermolecular hydrogen bonding with Trp, Scheme 2 presents the most probable structures of complexes formed between II and Trp molecule. As can be seen, the Trp residue was attached to the investigated molecules only at the sites considered important for hydrogen bond formation. It is obvious that actual situation in I-BSA, II-BSA, I-Trp and II-Trp systems is not simple, but the considered model can give a first insight into the specific Trp-methyl benzoate derivative interactions. In future works, separate molecular docking studies will be used to confirm the most probable binding site with BSA.
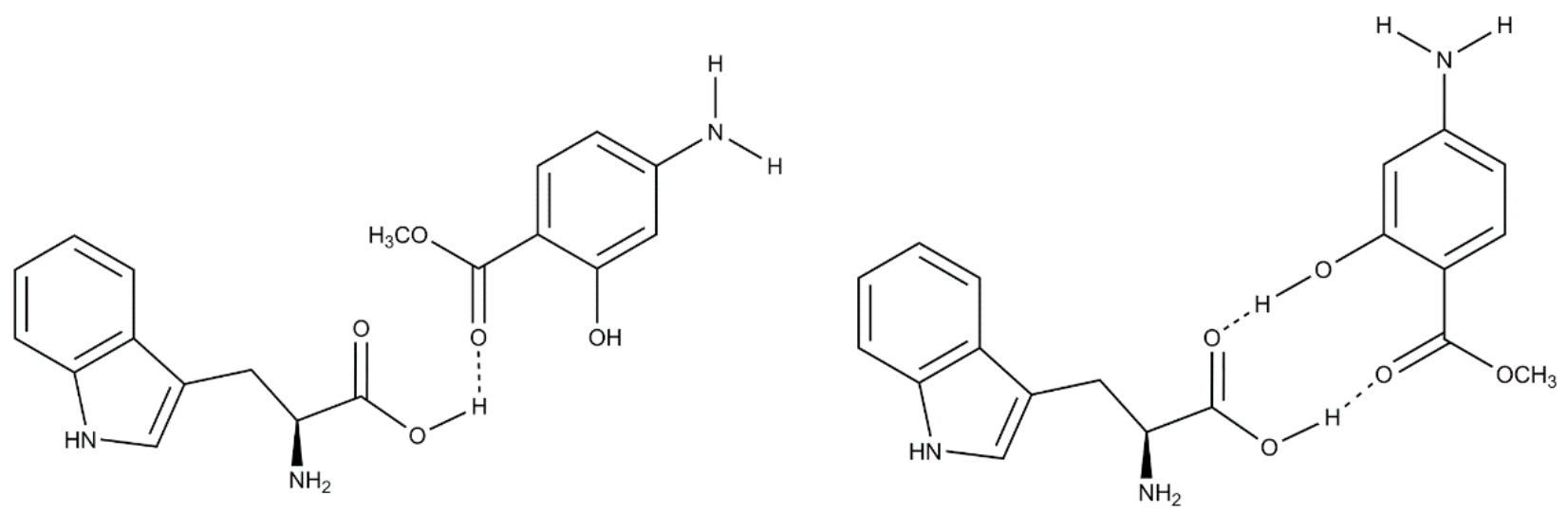

Scheme 2. Two of the possible structures of complexes formed between II and Trp molecule.

\subsection{Effect of I and II on the Steady-State and Time-Resolved Spectroscopic Behaviour of BSA and Trp}

In order to clarify the interaction process between two methyl benzoate derivatives and BSA and Trp, we have also carried out a series of the steady-state absorption and fluorescence studies of BSA and Trp in the presence of $\mathbf{I}$ and II. To begin with, Figures 7 and $\mathrm{S} 3$ show the changes observed in the absorption $(\mathrm{A}, \mathrm{B})$ and emission $\left(\mathrm{A}^{\prime}, \mathrm{B}^{\prime}\right)$ spectra of BSA (Figure 7) and Trp (Figure S3) in the phosphate buffer upon the gradual addition of I $\left(A, \mathrm{~A}^{\prime}\right)$ and II $\left(\mathrm{B}, \mathrm{B}^{\prime}\right)$. In order to better visualize the changes in the absorption spectra in the long-wavelength (LW) region (250-340 nm), the normalized LW absorption bands (by scaling the area under the spectrum to be equal to unity) are presented in insert of Figures 7 and S3. For both investigated systems (BSA-investigated molecules and Trp-investigated molecules), upon the gradual addition of the methyl benzoate derivative to the aqueous buffer solution of BSA (or Trp), the absorbance of the short-wavelength (centred at about $210 \mathrm{~nm}$ (BSA-I and BSA-II) and $218 \mathrm{~nm}$ (Trp-I and Trp-II)) and long-wavelength (centred at about $280 \mathrm{~nm}$ (BSA-I and BSA-II) and $275 \mathrm{~nm}$ (Trp-I and Trp-II)) bands gradually increases and simultaneously a new absorption band centred at around $310 \mathrm{~nm}$ appears. An isosbestic point in normalized LW absorption bands can be clearly seen between these two bands (see insert of Figures 7 and S3), which confirms formation of the ground-state complex between BSA or Trp and both investigated dyes. 


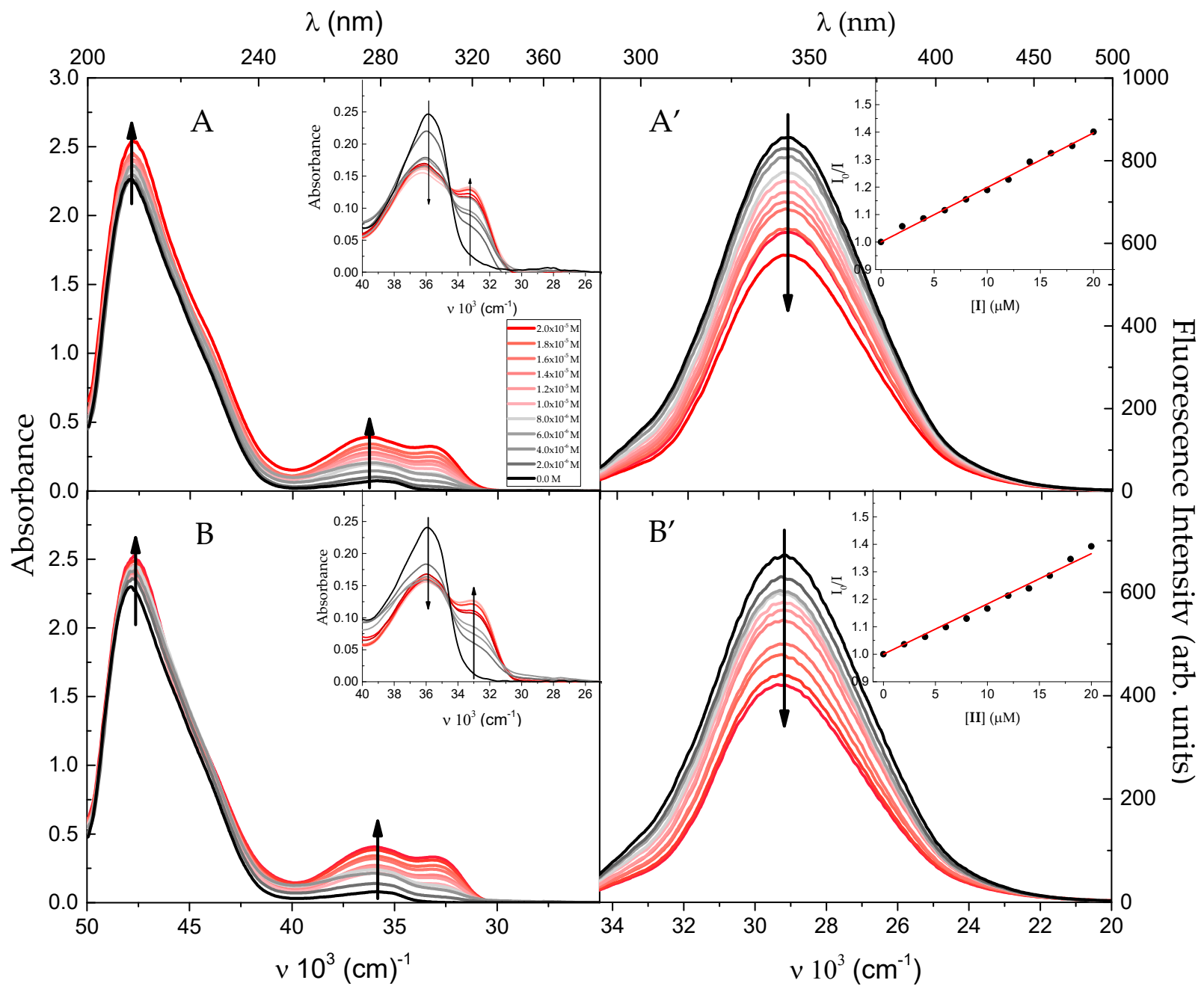

Figure 7. Absorption and fluorescence spectra $\left(\lambda_{\text {exc. }}=280 \mathrm{~nm}\right)$ of BSA $\left(\mathrm{c}=2 \times 10^{-6} \mathrm{M}\right)$ in phosphate buffer solutions containing different concentration of $\mathbf{I}\left(\mathbf{A}, \mathbf{A}^{\prime}\right)$ and $\mathbf{I I}\left(\mathbf{B}, \mathbf{B}^{\prime}\right)\left(0 \mathrm{M}, 2.0 \times 10^{-6} \mathrm{M}, 4.0 \times 10^{-6} \mathrm{M}, 6.0 \times 10^{-6} \mathrm{M}, 8.0 \times 10^{-6} \mathrm{M}\right.$, $\left.1.0 \times 10^{-5} \mathrm{M}, 1.2 \times 10^{-5} \mathrm{M}, 1.4 \times 10^{-5} \mathrm{M}, 1.6 \times 10^{-5} \mathrm{M}, 1.8 \times 10^{-5} \mathrm{M}, 2.0 \times 10^{-5} \mathrm{M}\right)$. The normalized LW absorption bands (by scaling the area under the spectrum to be equal to unity) are presented in insert of $(\mathbf{A}, \mathbf{B})$. The insert in $\left(\mathbf{A}^{\prime}, \mathbf{B}^{\prime}\right)$ shows a graphical presentation of the relationship between $\mathrm{I}_{0} / \mathrm{I}$ versus (I) ( $\left.\mathbf{A}^{\prime}\right)$ and (II) $\left(\mathbf{B}^{\prime}\right)$.

The interactions of BSA and Trp with two studied dyes were also investigated by the fluorescence quenching spectroscopy. In both cases (BSA and Trp), the addition of methyl benzoate derivative to a solution of BSA (or Trp) quenches significantly the single, broad fluorescence band centred at about $340 \mathrm{~nm}$ (BSA) and $352 \mathrm{~nm}$ (Trp) (registered upon excitation at $280 \mathrm{~nm}$ ) without significant changes in the shape of the fluorescence spectrum (see Figures 7 and S3). There is no shift in the wavelength of maximum intensity of BSA and Trp when it was quenched by I and II.

Using data obtained from the absorption and fluorescence titration experiments (BSAinvestigated molecules and Trp-investigated molecules), the Benesi-Hildebrand plots were constructed (Figure S4). Since the plots of $1 /\left(A-A_{0}\right)$ versus $1 /[\mathbf{I}](1 /[\mathbf{I I}])$ and $1 /\left(I-I_{0}\right)$ versus $1 /[\mathbf{I}](1 /[\mathbf{I I}])$ produce a straight line for both systems with a good correlation coefficient $(r>0.95)$, the stoichiometry of the formed complexes between BSA (Trp) and methyl benzoate derivatives in the ground and excited states is 1:1. The binding constants were found to be $(2.1 \pm 0.1) \times 10^{4} \mathrm{M}^{-1}$ and $(2.4 \pm 0.1) \times 10^{4} \mathrm{M}^{-1}$ in the ground state and $(2.0 \pm 0.1) \times 10^{4} \mathrm{M}^{-1}$ and $(2.7 \pm 0.1) \times 10^{4} \mathrm{M}^{-1}$ in the excited state, for BSA-I and BSA-II, respectively and $(2.0 \pm 0.1) \times 10^{4} \mathrm{M}^{-1}$ and $(2.2 \pm 0.1) \times 10^{4} \mathrm{M}^{-1}$ in the ground state and $(1.8 \pm 0.1) \times 10^{4} \mathrm{M}^{-1}$ and $(2.4 \pm 0.1) \times 10^{4} \mathrm{M}^{-1}$ in the excited state, for Trp-I and Trp-II, 
respectively. It is clearly seen that they are in a good agreement with data presented in previous section (Section 2.1). The binding constant values determined on the basis of the two independent titration experiments differ by about $10 \%$.

In order to confirm the existence of the ground and excited states complexes (BSA-I and BSA-II, as well as Trp-I and Trp-II) and the 1:1 stoichiometry of the complexes, the results of the steady-state spectroscopic measurements are analysed using the Job's plot technique (continuous variation method) [43]. Job plots were generated by plotting the difference in absorbance (ground state complex) or fluorescence intensity (excited state complex) versus the mole fraction of the investigated dye (R) in the used solutions (Figure S5). The curve maximum at about 0.5 supports the previously mentioned $1: 1$ stoichiometry in the ground and excited states i.e., the number of I (or II) molecules binding to BSA and Trp is close to unity.

\subsubsection{Mechanism of the Observed Fluorescence Quenching}

It is well known that the progressive fluorescence quenching can be explained by three main reasons: static quenching (nonfluorescent complex is formed between fluorophore and quencher), dynamic (resulting from collisional encounters between fluorophore and quencher) and quenching both by collisions and complex formation [38]. In order to determine the extent and mechanism of the fluorescence quenching of BSA by I and II molecules, the results of spectroscopic measurements are analysed using Stern-Volmer equation (see Equation (3)). As can be seen in insert of Figure 7, the Stern-Volmer plot $\left(I_{0} / I\right.$ versus [I] and [II]) at $298 \mathrm{~K}$ is linear for both systems, which indicates that only one type of quenching occurs (static or dynamic). The $\mathrm{K}_{\mathrm{SV}}$ values obtained from linear plots are listed in Table 3. From the $\mathrm{K}_{\mathrm{SV}}$ values obtained for both of the systems at room temperature $(298 \mathrm{~K})$, it is evident that the molecule II has only a slightly stronger binding affinity for BSA in comparison to I (the ratio of the corresponding Stern-Volmer quenching constant, $K_{S V}(\mathbf{I}) / K_{S V}(\mathbf{I I})$, is about 1.05).

Table 3. Stern-Volmer quenching constant $\left(K_{S V}\right)$, binding constant determined using BenesiHildebrand $\left(K_{B H}\right)$ and Scatchard $\left(K_{b}\right)$ methods and thermodynamic parameters (binding number (n), changes in enthalpy $(\Delta H)$, entropy $(\Delta S)$, and Gibb's free energy $(\Delta G)$ of the binding process) at different temperatures.

\begin{tabular}{|c|c|c|c|c|c|c|c|c|}
\hline Molecule & $\begin{array}{l}\text { Temp. } \\
\text { (K) }\end{array}$ & $\begin{array}{c}K_{S V} 1^{4} \\
\left(\mathbf{M}^{-1}\right)\end{array}$ & $\begin{array}{c}K_{B H} 10^{4} \\
\left(\mathbf{M}^{-1}\right)\end{array}$ & $\begin{array}{l}K_{b} 10^{4} \\
\left(M^{-1}\right)\end{array}$ & $n$ & $\Delta H(\mathrm{~kJ})$ & $\Delta S(\mathrm{~J})$ & $\Delta G(\mathrm{~kJ})$ \\
\hline \multirow{4}{*}{ I } & 278 & 2.4 & 2.6 & 3.5 & 1.07 & \multirow{4}{*}{-25.66} & \multirow{4}{*}{-4.86} & -24.308 \\
\hline & 288 & 2.1 & 2.4 & 2.7 & 1.04 & & & -24.260 \\
\hline & 298 & 1.9 & 2.0 & 2.1 & 1.00 & & & -24.211 \\
\hline & 303 & 1.5 & 1.3 & 1.3 & 0.93 & & & -24.187 \\
\hline \multirow{4}{*}{ II } & 278 & 2.6 & 3.6 & 3.5 & 1.07 & \multirow{4}{*}{-25.12} & \multirow{4}{*}{-2.17} & -24.512 \\
\hline & 288 & 2.2 & 3.0 & 3.0 & 1.05 & & & -24.491 \\
\hline & 298 & 1.8 & 2.7 & 2.7 & 1.02 & & & -25.469 \\
\hline & 303 & 1.5 & 1.8 & 1.3 & 0.99 & & & -25.458 \\
\hline
\end{tabular}

Because character of fluorescence quenching (static versus dynamic) can be differentiated by their different dependence on temperature (higher temperatures result in faster diffusion and dissociation of weakly bound complexes), temperature-dependent fluorescence spectral measurements were conducted at four different temperatures, and data are analysed using Stern-Volmer relation. Plots of $I_{0} / I$ versus [I] and [II] at four temperatures are shown in Figure 8. Analysing the $\mathrm{K}_{\mathrm{SV}}$ values (obtained at different temperatures) assembled in Table 3, in connection with the graphical presentation in Figure 8, it is evident that the quenching mechanism of the investigated systems is sensitive to temperature. As 
can be seen, upon increasing the temperature, $\mathrm{K}_{\mathrm{SV}}$ value decreases, which indicates that the quenching process is static i.e., complex is formed between I (or II) and BSA.

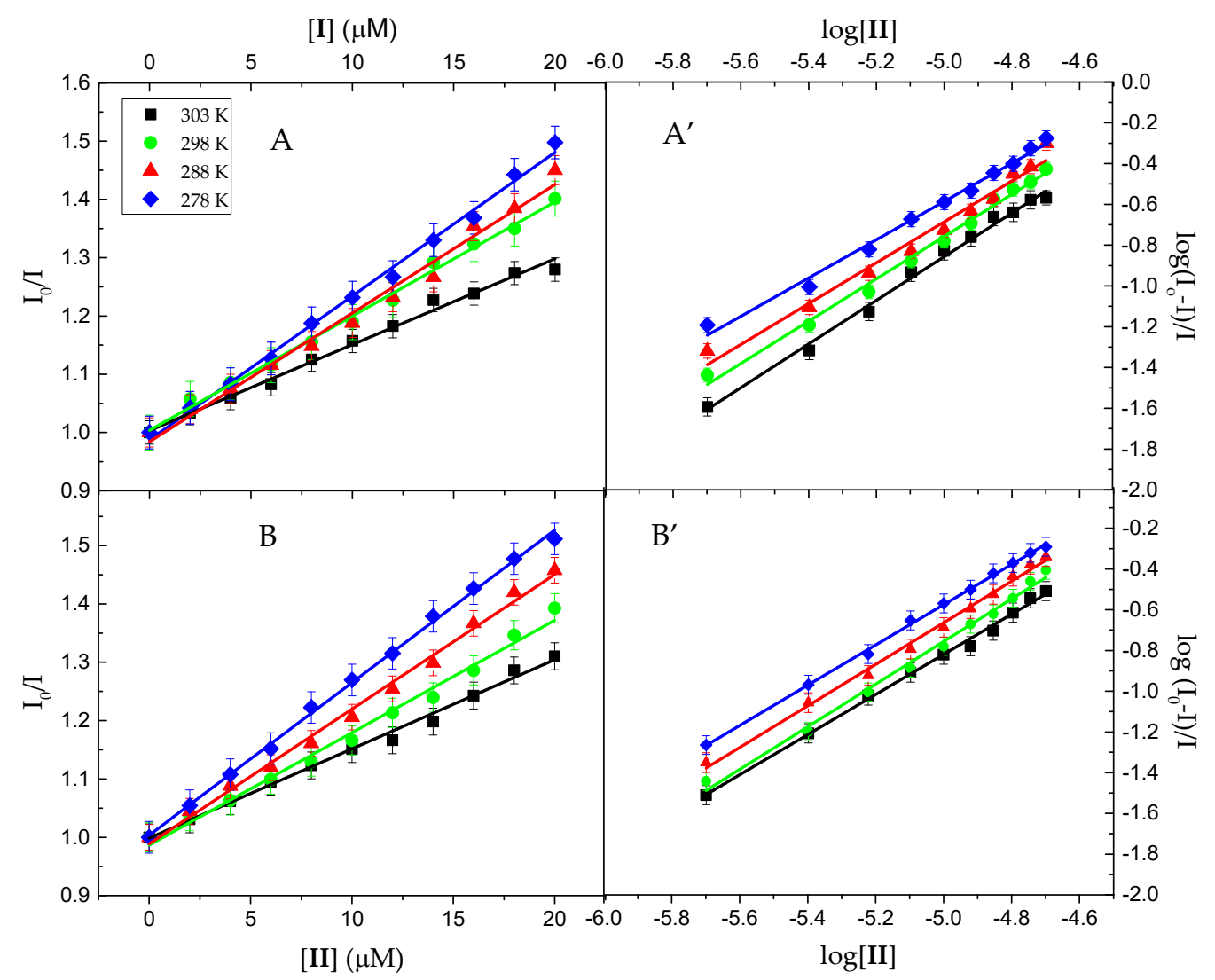

Figure 8. Stern-Volmer $(\mathbf{A}, \mathbf{B})$ and $\log \left(\mathrm{I}_{0}-\mathrm{I}\right) / \mathrm{I}$ versus $\log ($ molecule $)\left(\mathbf{A}^{\prime}, \mathbf{B}^{\prime}\right)$ plots for quenching of BSA by $\mathbf{I}\left(\mathbf{A}, \mathbf{A}^{\prime}\right)$ and II $\left(\mathbf{B}, \mathbf{B}^{\prime}\right)$ at different temperatures.

Static character of fluorescence quenching is also confirmed by temperature-dependent Benesi-Hildebrand plot experiment. The plots of $1 /\left(I-I_{0}\right)$ follow a linear dependence on $1 /[\mathbf{I}](1 /[\mathbf{I I}])$ for four investigated temperatures (278-303 K). This finding indicates 1:1 complex formation between studied compounds and BSA at all temperatures. As seen in Table 3, the increase of the solute temperature from 278 to $303 \mathrm{~K}$ results also in the decrease of binding constant $\left(K_{B H}\right)$ value by a factor of 2 (for BSA-I system) and 1.5 (for BSA-II), which confirms the occurrence of static quenching mechanism - higher temperatures results in dissociation of weakly bound complexes.

It is well-known that the analysis of fluorescence kinetics is the most definite method to distinguish the character of fluorescence quenching (static versus dynamic) [38]. For static quenching, the fluorescence lifetime of the investigated molecule remains unchanged in the presence of a quencher, while for dynamic quenching $\tau_{0} / \tau \neq 1$. In order to further confirm the quenching mechanism, time-resolved emission spectra of BSA upon gradual addition of I and II were recorded. The lifetime parameters presented in Table 4 show that fluorescence decays consist of a fast ( 1 ns (10\%)) and a slow ( 5.6 ns $(90 \%))$ components, with an average time $\sim 5.2 \mathrm{~ns}$. The nonexponential kinetic traces of the native BSA has been described previously and most probably they can be assigned to the presence of two Trp moieties at distinct conformational states [21]. It is clearly seen that the average lifetime of BSA is practically unchanged in the presence of different concentrations of I and II, which confirms our previous conclusions drawn from the analysis of the steady-state spectroscopic measurements described above i.e., static quenching mechanism between BSA and I (or II). Moreover, the high value of the quenching rate constant at room temperature 
$\left(k_{q}(\mathbf{I})=K_{S V}(\mathbf{I}) /<\tau_{0}>=3.6 \times 10^{12} \mathrm{M}^{-1} \mathrm{~s}^{-1}, k_{q}(\mathbf{I I})=K_{S V}(\mathbf{I I}) /<\tau_{0}>=3.4 \times 10^{12} \mathrm{M}^{-1} \mathrm{~s}^{-1}\right)$, which is much higher than typical diffusion-controlled quenching rate constants $\left(2 \times 10^{10} \mathrm{M}^{-1} \mathrm{~s}^{-1}\right)$ excludes dynamic character of the quenching process (diffusion controlled reaction).

Table 4. BSA fluorescence lifetimes as a function of I and II concentration at room temperature.

\begin{tabular}{|c|c|c|c|c|c|c|c|}
\hline Molecule & $\begin{array}{l}\text { Molecule Concentration } \\
\qquad 10^{-5}(\mathrm{M})\end{array}$ & $\begin{array}{c}\tau_{1} \\
(\mathrm{~ns})\end{array}$ & $\begin{array}{l}A_{1} \\
(\%)\end{array}$ & $\begin{array}{c}\tau_{2} \\
(\mathrm{~ns})\end{array}$ & $\begin{array}{l}A_{2} \\
(\%)\end{array}$ & $\begin{array}{l}<\tau> \\
\text { (ns) }\end{array}$ & $\mathrm{r}^{2}$ \\
\hline \multirow{6}{*}{ I } & 0 & 0.98 & 6.6 & 5.59 & 93.4 & 5.28 & 0.99 \\
\hline & 0.4 & 0.98 & 7.8 & 5.70 & 92.2 & 5.35 & 0.99 \\
\hline & 0.8 & 0.93 & 10.4 & 5.64 & 89.6 & 5.15 & 0.99 \\
\hline & 1.2 & 0.87 & 12.8 & 5.49 & 87.2 & 4.89 & 0.99 \\
\hline & 1.6 & 0.91 & 10.8 & 5.55 & 89.2 & 5.05 & 0.99 \\
\hline & 2.0 & 0.91 & 13.2 & 5.56 & 86.8 & 4.94 & 0.99 \\
\hline \multirow{6}{*}{ II } & 0 & 0.98 & 6.6 & 5.59 & 93.4 & 5.28 & 0.99 \\
\hline & 0.4 & 0.97 & 7.2 & 5.58 & 92.8 & 5.25 & 0.99 \\
\hline & 0.8 & 1.01 & 10.8 & 5.68 & 89.2 & 5.18 & 0.99 \\
\hline & 1.2 & 0.96 & 11.5 & 5.53 & 88.5 & 5.02 & 0.99 \\
\hline & 1.6 & 0.83 & 10.4 & 5.40 & 89.6 & 4.93 & 0.99 \\
\hline & 2.0 & 0.97 & 9.6 & 5.70 & 90.4 & 5.24 & 0.99 \\
\hline
\end{tabular}

\subsubsection{Thermodynamic Parameters}

To support the above conclusions i.e., the number of binding sites per protein molecule (n) and binding constant value, we also analysed the fluorescence quenching data using Scatchard equation (Equation (4)). As seen in Figure 8, the linear dependence between $\log \left(\frac{I_{0}-I}{I}\right)$ and $\log [\mathbf{I}]$ (and $\left.\log [\mathbf{I I}]\right)$ is obtained at four temperatures studied. The slope and the intercept values were therefore obtainable and used to calculate $n$ and $K_{b}$. The results are assembled in Table 3 . The calculated, temperature-dependent $K_{b}$ values confirm that the fluorescence quenching has a static character, in agreement with the expectation that the binding constant for the static quenching decreases with increasing temperature. Moreover, $K_{b}$ values correlate well with the alternatively calculated binding constant $\left(K_{B H}\right)$ using Benesi-Hildebrand relation (see Table 3). Finally, $n$ values (found to be about 1 for both studied systems) further confirm the 1:1 stoichiometry of the complexes.

In order to understand the role of different types of non-covalent interactions, namely, van der Waals forces, multiple hydrogen-bonding, hydrophobic, and electrostatic interactions, in the binding of I (or II) with BSA, related thermodynamic characteristics were estimated by using the van't Hoff equation (Equation (5)). The values of $\Delta H$ and $\Delta S$ are determined from the slope and intercept of the plot of $\ln K_{b}$ versus $1 / T$ for four different temperatures and presented in Table 3 . The negative free energy change $(\Delta G)$ value determined for both systems indicates that the interaction of BSA with two studied dyes is a spontaneous reaction. Moreover, from the magnitude and the sign of the $\Delta S$ and $\Delta H$ thermodynamic parameters $(\Delta S<0, \Delta H<0$ and $|\Delta H| \gg|\Delta S|)$, it can also be deduced that: (i) BSA-I and BSA-II interaction is an exothermic reaction (negative enthalpy change, $\Delta H<0$ ); (ii) reaction is more enthalpy-driven (negative entropy change $(\Delta S<0)$ is balanced by highly negative enthalpy change $(\Delta H<0)$ i.e., $|\Delta H| \gg|\Delta S|$; (iii) hydrogen bonding and weak van der Waals forces play a crucial role in methyl benzoate derivative-BSA interactions. 


\section{Materials and Methods}

\subsection{Reagents and Materials}

Bovine serum albumin (BSA, min. 98\%, from Sigma-Aldrich, St. Louis, MO, USA) and tryptophan (Trp, 98\%, from Sigma-Aldrich), tyrosine (Tyr, 98\%, from Sigma-Aldrich), phenylalanine (Phe, $98 \%$, from Sigma-Aldrich) and phosphate buffer solution ( $\mathrm{pH} 7.4$ ) were used as received. The methyl $o$-methoxy $p$-methylaminobenzoate-I and methyl $o$-hydroxy $p$-methylaminobenzoate-II have been synthesized and purified by Gormin [44-46]. The purity of dyes was controlled by thin layer chromatography.

\subsection{Apparatus and Methods}

\subsubsection{Steady-State and Time-Resolved Measurements}

Absorption and fluorescence spectra were recorded using, respectively, a Shimadzu UV-2401 PC spectrophotometer and Shimadzu RF-5301 PC spectrofluorometer. The emission spectra were corrected for the spectral response of the photomultiplier (Hamamatsu R-928) and monochromator pass, but not for reabsorption which was negligible in these samples. Time-resolved emission spectra were taken with the steak camera (C4334-01 Hamamatsu) and $2501 \mathrm{~S}$ spectrograph system (Bruker Optics). Solid state Nd: YAG laser (PL 2143A/SS EKSPLA) and optical parametric generator (PG 401/SH EKSPLA) were used as the picosecond excitation light pulses source [47].

\subsubsection{Determination of Stoichiometry and Binding Constants}

The determination of the ground $(g)$ and excited $(e)$ state binding constant and stoichiometry of the formed complex

$$
X+Y \stackrel{K_{1}^{e}(g)}{\leftrightarrow}(X: Y)+Y \stackrel{K_{\stackrel{e}{(}(g)}^{\rightarrow}}{\longrightarrow}\left(X: Y_{2}\right)
$$

can be determined by analysing the changes in the absorbance and/or fluorescence intensity of the molecule $X$ in the presence of $Y$. From the fluorescence (absorption) titration data, the binding constant was determined by Benesi-Hildebrand equation [48]:

$$
\begin{aligned}
\frac{1}{A-A_{0}} & =\frac{1}{K_{n}^{g}\left(A_{1}-A_{0}\right)} \cdot \frac{1}{[Y]^{n}}+\frac{1}{A_{1}-A_{0}} \\
\frac{1}{I-I_{0}} & =\frac{1}{K_{n}^{e}\left(I_{1}-I_{0}\right)} \cdot \frac{1}{[Y]^{n}}+\frac{1}{I_{1}-I_{0}}
\end{aligned}
$$

In Equation (2), $n$ is binding stoichiometry, $I_{0}\left(A_{0}\right), I(A)$ and $I_{1}\left(A_{1}\right)$ are the fluorescence intensities (or absorbances) of the molecule $X$, respectively in the absence of $Y$, intermediate and at infinite concentration of $Y$. Thus, the $1 /\left(I-I_{0}\right)$ (or $\left.1 /\left(A-A_{0}\right)\right)$ should follow a linear dependence on $1 /[Y]^{n}$ for the correct stoichiometry $(n)$.

The binding stoichiometry was also determined from Job's method (continuous variation method) [43]. Job plots were constructed by plotting the difference in absorbance and/or fluorescence intensity $(\Delta A(\Delta I))$ of $X$ observed in the presence of $Y$ against the mole fraction of the dye $X\left(\mathrm{x}_{\mathrm{x}}\right)$. The value of mole fraction of $X$ at the maximum deviation yields the stoichiometry of the formed complex i.e., stoichiometry of $X: Y$ complex is 1:2 if $x_{x}=0.33 ; 1: 1$ if $x_{x}=0.5 ; 2: 1$ if $x_{x}=0.66$ etc.

\subsubsection{Analysis of Fluorescence Quenching Data}

In order to determine the extent and mechanism of the fluorescence quenching, the results of spectroscopic measurements are analysed using Stern-Volmer equation [38]:

$$
\frac{I_{0}}{I}=1+k_{q} \tau_{0}[Q]=1+K_{S V}[Q]
$$


where $I_{0}$ and $I$ are the fluorescence intensities in the absence and presence of different concentration of quencher $([Q])$, respectively. $k_{q}, \tau_{0}$ and $K_{S V}$ are bimolecular quenching constant, average fluorescence lifetime of the molecule in the absence of quencher and Stern-Volmer quenching constant, respectively.

Additionally, using fluorescence quenching data, Scatchard equation (Equation (4)) was employed to estimate the binding constant $\left(K_{b}\right)$ and the number of binding sites per protein molecule $(n)$ [49-51]:

$$
\log \frac{I_{0}-I}{I}=\log K_{b}+n \log [Q]
$$

\subsubsection{Analysis of Thermodynamic Parameters}

The related thermodynamic characteristics were determined from the van't Hoff equation [52]:

$$
\ln K_{b}=-\frac{\Delta H}{R T}+\frac{\Delta S}{R}
$$

where $K_{b}$ is the binding constant at temperature $T$ and $R$ is universal gas constant, $\Delta H$ and $\Delta S$ are the changes in enthalpy and entropy of the binding process. The Gibb's free energy change $(\Delta G)$ during the binding processes was calculated by using the equation:

$$
\Delta G=\Delta H-T \Delta S
$$

at each corresponding temperature.

\subsubsection{Analysis of Supramolecular Solvation Dynamics}

The supramolecular solvation dynamics was analysed by the decay of the solvation correlation function $c(t)$, defined by Maroncelli and Fleming as [39,40]:

$$
c(t)=\frac{\widetilde{v}(t)-\widetilde{v}(\infty)}{\widetilde{v}(0)-\widetilde{v}(\infty)}
$$

where $\widetilde{v}(t), \widetilde{v}(0)$, and $\widetilde{v}(\infty)$ are the wavenumbers of the fluorescence band maximum at times $\mathrm{t}, 0$, and $\infty$. The decay of the solvation correlation function, $c(t)$, was fitted to an exponential decay:

$$
c(t)=\sum_{i=1}^{N} A_{i} e^{-t / \tau_{i}} .
$$

\section{Conclusions}

In the present work, an attempt was made to understand the nature and mechanisms of interactions between two selected methyl benzoate derivatives (I and II) and bovine serum albumin. In order to clarify the role of Trp residue of BSA in the I-BSA and II-BSA interaction phenomenon, I-Trp and II-Trp systems were also investigated. Experimental results show that the investigated interactions (with both BSA and Trp) are mainly based on the ground- and excited-state complex formation processes. Both molecules form a stable complex with BSA and Trp (with 1:1 stoichiometry) in the ground and excited states. The binding constant was in the order of $10^{4} \mathrm{M}^{-1}$. Moreover, our experimental data clearly indicate that mainly Trp residue of BSA is involved in the process of specific interaction between I (or II) and BSA.

The fluorescence quenching studies along with time-resolved fluorescence measurements show that the binding of the I and II causes fluorescence quenching of BSA through a static mechanism, revealing a 1:1 interaction. The binding reaction is associated with the negative $\Delta S, \Delta H$ and $\Delta G$ which implies that the hydrogen bonding and van der Waals forces play major roles in stabilizing the complex. Moreover, the reaction is spontaneous, exothermic and more enthalpy-driven. Finally, our studies have shown that solvation dynamics, which occurs in subpicosecond time scale in neat solvents of different polarities, 
is slowed down significantly when organic molecule is transferred to BSA cavity. In future works, separate molecular docking studies will be used to confirm the most probable binding site with BSA.

Supplementary Materials: The following are available online at https:/ / www.mdpi.com/article/10 $.3390 /$ ijms222111705/s1.

Author Contributions: Conceptualization, K.B. and M.J.; methodology, K.B. and M.J.; software, K.B. and M.M.; validation, K.B. and M.J.; formal analysis, K.B. and M.J.; investigation, K.B. and M.M.; resources, K.B.; data curation, K.B.; writing-original draft preparation, K.B. and M.J.; writingreview and editing, K.B., M.J. and P.B.; visualization, K.B. and M.J.; supervision, M.J.; project administration, M.J.; funding acquisition, M.J. and P.B. All authors have read and agreed to the published version of the manuscript.

Funding: This research was funded by the Research Grant BW for Young Scientists from the University of Gdańsk, grant number BMN 538-5200-B045-18.

Institutional Review Board Statement: Not applicable.

Informed Consent Statement: Not applicable.

Data Availability Statement: Not applicable.

Conflicts of Interest: The authors declare no conflict of interest.

\section{References}

1. Webber, M.J.; Langer, R. Drug delivery by supramolecular design. Chem. Soc. Rev. 2017, 46, 6600-6620. [CrossRef]

2. Dsouza, R.N.; Pischel, U.; Nau, W.M. Fluorescent Dyes and Their Supramolecular Host/Guest Complexes with Macrocycles in Aqueous Solution. Chem. Rev. 2011, 111, 7941-7980.

3. Delbianco, M.; Bharate, P.; Varela-Arambura, S.; Seeberger, P.H. Carbohydrate in Supramolecular Chemistry. Chem. Rev. 2016, 116, 1693-1752. [PubMed]

4. Mako, T.L.; Racicot, J.M.; Levine, M. Supramolecular Luminescent Sensors. Chem. Rev. 2019, 119, 322-477. [CrossRef] [PubMed]

5. Pinalli, R.; Pedrini, A.; Dalcanale, E. Biochemical sensing with macrocyclic receptors. Chem. Soc. Rev. 2018, 47, 7006-7026. [CrossRef] [PubMed]

6. Liu, Z.; Nalluri, S.K.M.; Stoddart, J.F. Surveying macrocyclic chemistry: From flexible crown ethers to rigid cyclophanes. Chem. Soc. Rev. 2017, 46, 2459-2478. [CrossRef]

7. Parks, F.C.; Liu, Y.; Debnath, S.; Stutsman, S.R.; Raghavachari, K.K.; Flood, A.H. Allosteric Control of Photofoldamers for Selecting between Anion Regulation and Double-to-Single Helix Switching. J. Am. Chem. Soc. 2018, 140, 17711-17723. [CrossRef]

8. Dobscha, J.R.; Debnath, S.; Fadler, R.E.; Fatila, E.; Pink, M.; Raghavavhari, K.; Flood, A.H. Host-Host Interaction Control Selfassembly and Switching of Triple and Double Decker Stacks of Tricarbazole Macorocycles Coassembled with anti-Electrostatic Bisulfate Dimers. Chem. Eur. J. 2018, 24, 9841-9852. [CrossRef]

9. Buschmann, H.J.; Schollmeyer, E. Applications of cyclodextrins in cosmetic products: A review. J. Cosmet. Sci. 2002, 53, 185-191.

10. Loh, X.J. Supramolecular host-guest polymeric materials for biomedical applications. Mater. Horiz. 2014, 1, $185-195$.

11. Marsault, E.; Peterson, M.L. Macrocycles Are Great Cycles: Applications, Opportunities, and Challenges of Synthetic Macrocycles in Drug Discovery. J. Med. Chem. 2011, 54, 1961-2004. [CrossRef]

12. Singh, M.; Sharma, R.; Banerjee, U.C. Biotechnological applications of cyclodextrins. Biotechnol. Adv. 2002, 20, 341-359. [CrossRef]

13. Loftsson, T.; Masson, M. Cyclodextrins in topical drug formulations: Theory and practice. Int. J. Pharm. 2001, 225, 15-30. [CrossRef]

14. Martin Del Valle, E.M. Cyclodextrins and their uses: A review. Process Biochem. 2004, 39, 1033-1046. [CrossRef]

15. Bhuiya, S.; Pradhan, A.B.; Haque, L.; Das, S. Molecular Aspects of the Interaction of Iminium and Alkanolamine Forms of the Anticancer Alkaloid Chelerythrine with Plasma Protein Bovine Serum Albumin. J. Phys. Chem. B 2016, 120, 5-17. [CrossRef] [PubMed]

16. Ray, D.; Kundu, A.; Pramanik, A.; Guchhait, N. Exploring the Interaction of a Micelle Entrapped Biologically Important Proton Transfer Probe with the Model Transport Protein Bovine Serum Albumin. J. Phys. Chem. B 2015, 119, 2168-2179. [CrossRef] [PubMed]

17. Bolattin, M.B.; Nandibewoor, S.T.; Joshi, S.D.; Dixit, S.R.; Chimatadar, S.A. Interaction of Hydralazine with Human Serum Albumin and Effect of $\beta$-Cyclodextrin on Binding: Insights from Spectroscopic and Molecular Docking Techniques. Ind. Eng. Chem. Res. 2016, 55, 5454-5464. [CrossRef]

18. Rabbani, G.; Baig, M.H.; Lee, E.J.; Cho, W.K.; Ma, J.; Choi, I. Biophysical Study on the Interaction between Eperisone Hydrochloride and Human Serum Albumin Using Spectroscopic, Calorimetric, and Molecular Docking Analyses. Mol. Pharm. 2017, 14, 1656-1665. [CrossRef] 
19. Rabbani, G.; Lee, E.J.; Ahmad, K.; Baig, M.H.; Choi, I. Binding of Tolperisone Hydrochloride with Human Serum Albumin: Effects on the Conformation, Thermodynamics, and Activity of HSA. Mol. Pharm. 2018, 15, 1445-1456. [CrossRef]

20. Sasmal, M.; Islam, A.S.M.; Bhowmick, R.; Maiti, D.; Dutta, A.; Ali, M. Site-Selective Interaction of Human Serum Albumin with 4-Chloro-7-nitro-1,2,3-benzoxadiazole Modified Olanzapine Derivative and Effect of $\beta$-Cyclodextrin on Binding: In the Light of Spectroscopy and Molecular Docking. ACS Appl. Biol. Mater. 2019, 2, 3551-3561. [CrossRef]

21. Ghosh, S.; Dey, J. Binding of Fatty Acid Amide Amphiphiles to Bovine Serum Albumin: Role of Amide Hydrogen Bonding. J. Phys. Chem. B 2015, 119, 7804-7815. [CrossRef] [PubMed]

22. Cohen, B.; Álvarez, C.M.; Carmona, N.A.; Organero, J.A.; Douhal, A. Proton-Transfer Reaction Dynamics within the Human Serum Albumin Protein. J. Phys. Chem. B 2011, 115, 7637-7647. [CrossRef] [PubMed]

23. Sasmal, M.; Bhowmick, R.; Islam, A.S.M.; Bhuiya, S.; Das, S.; Ali, M. Domain-Specific Association of a Phenanthrene-PyreneBased Synthetic Fluorescent Probe with Bovine Serum Albumin: Spectroscopic and Molecular Docking Analysis. ACS Omega 2018, 3, 6293-6304. [CrossRef] [PubMed]

24. Peters, T. All about Albumin: Biochemistry, Genetics and Medical Applications; Academic Press: San Diego, CA, USA, 1995.

25. Carter, D.C.; Ho, J.X. Structure of Serum Albumin. Adv. Protein Chem. 1994, 45, 153-203.

26. Foster, J.F. Albumin Structure, Function and Uses; Pergamon Press: Oxford, UK, 1977.

27. He, X.M.; Carter, D.C. Atomic Structure and Chemistry of Human Serum Albumin. Nature 1992, 358, 209-215. [CrossRef] [PubMed]

28. Aleksiejew, M.; Heldt, J.; Heldt, J.R. Experimental and theoretical spectroscopic studies of ortho derivatives of methyl $p$ dimethylaminobenzoate. J. Lumin. 2009, 129, 208-220. [CrossRef]

29. Józefowicz, M.; Aleksiejew, M.; Heldt, J.R.; Heldt, J. Ground and excited state dipole moments of ortho derivatives of methyl p-dimethylaminobenzoate. J. Mol. Liq. 2010, 157, 61-66. [CrossRef]

30. Józefowicz, M.; Aleksiejew, M.; Abramov, A.V.; Ling, S.; Gutowski, M.; Heldt, J.; Heldt, J.R. Influence of Prototropic Reactions on the Absorption and Fluorescence Spectra of Methyl $p$-dimethylaminobenzoate and Its Two Ortho Derivatives. J. Fluoresc. 2011, 21, 1749-1762. [CrossRef]

31. Józefowicz, M.; Heldt, J.R.; Heldt, J. Experimental and theoretical studies of electronic transition dipole moments of methyl benzoate derivatives. Lumin. J. 2012, 132, 755-764. [CrossRef]

32. Aleksiejew, M.; Heldt, J.; Heldt, J.R. Luminescence studies of $o$-hydroxy $p$-amino and $p$-dimethylamino methyl benzoate. J. Lumin. 2008, 128, 1307-1316. [CrossRef]

33. Lazarowska, A.; Józefowicz, M.; Heldt, J.R.; Heldt, J. Spectroscopic studies of inclusion complexes of methyl- $p$-dimethylaminobenzoate and its ortho derivatives with $\alpha$ - and $\beta$-cyclodextrins. Spectroch. Acta A 2012, 86, 481-489. [CrossRef] [PubMed]

34. Józefowicz, M. Effect of $\alpha$ - and $\beta$-cyclodextrins on the intramolecular charge transfer and intramolecular proton transfer fluorescence of methyl $o$-hydroxy $p$-dimethylaminobenzoate. Spectroch. Acta Part A 2012, 93, 169-175. [CrossRef] [PubMed]

35. Baranowska, K.; Józefowicz, M. Spectroscopic studies of inclusion complexation between ortho derivatives of $p$-methylaminobenzoate and $\alpha$ - and $\gamma$-cyclodextrins. J. Mol. Liq. 2018, 265, 140-150. [CrossRef]

36. Baranowska, K.; Bajorek, A.; Pietrzak, M.; Józefowicz, M. Preferential encapsulation of different conformers of ethyl 5-(4dimethylaminophenyl)-3-amino-2,4-dicyanobenzoate in $\gamma$-cyclodextrins. J. Mol. Liq. 2020, 302, 112430. [CrossRef]

37. Baranowska, K.; Mońka, M.; Kowalczyk, A.; Szpakowska, N.; Kaczyński, Z.; Bojarski, P.; Józefowicz, M. Spectroscopic studies of the excited-state intramolecular proton and electron transfer processes of methyl benzoate derivatives in cucurbit[7]uril nanocage. J. Mol. Liq. 2020, 318, 113921. [CrossRef]

38. Lakowicz, J.R. Principles of Fluorescence Spectroscopy; Springer: New York, NY, USA, 2006.

39. Maroncelli, M.; Fleming, G.R. Picosecond solvation dynamics of coumarin 153: The importance of molecular aspects of solvation. J. Phys. Chem. 1987, 86, 6221-6239. [CrossRef]

40. Fee, R.S.; Maroncelli, M. Estimating the time-zero spectrum in time-resolved emission measurements of solvation dynamics. Chem. Phys. 1994, 184, 235-247. [CrossRef]

41. Pal, S.K.; Mandal, D.; Sukul, D.; Sen, S.; Bhattacharyya, K. Solvation Dynamics of DCM in Human Serum Albumin. J. Phys. Chem. B. 2001, 105, 1438-1441. [CrossRef]

42. Mandal, D.; Sen, S.; Sukul, D.; Bhattacharyya, K.; Mandal, A.K.; Banerjee, R.; Roy, S. Solvation Dynamics of a Probe Covalently Bound to a Protein and in an AOT Microemulsion: 4-(N-Bromoacetylamino)-Phthalimide. J. Phys. Chem. B. 2002, 106, 10741-10747. [CrossRef]

43. Job, P. Formation and Stability of Inorganic Complexes in Solution. Ann. Chim. 1928, 9, 113-203.

44. Heldt, J.; Gormin, D.; Kasha, M. A comparative picosecond spectroscopic study of the competitive triple fluorescence of aminosalicylates and benzanilides. Chem. Phys. 1989, 136, 321-334. [CrossRef]

45. Gormin, D.; Kasha, M. Triple fluorescence in aminosalicylates. Modulation of normal, proton-transfer, and twisted intramolecular charge-transfer (TICT) fluorescence by physical and chemical perturbations. Chem. Phys. Lett. 1988, 153, 574-576. [CrossRef]

46. Gormin, D.; Heldt, J.; Kasha, M. Molecular Phosphorescence Enhancement via Tunneling through Proton-Transfer Potentials. J. Phys. Chem. 1988, 94, 1185-1189. [CrossRef]

47. Kubicki, A.A.; Bojarski, P.; Grinberg, M.; Sadownik, M.; Kukliński, B. Time-resolved streak camera system with solid state laser and optical parametric generator in different spectroscopic applications. Opt. Commun. 2006, 263, 275-280. [CrossRef] 
48. Hildebrand, J.H.; Benesi, H.A. A Spectrophotometric Investigation of the Interaction of Iodine with Aromatic Hydrocarbons. J. Am. Chem. Soc. 1949, 71, 2703-2707.

49. Connors, K.A. Binding Constants: The Measurements of Molecular Complex Stability; Wiley: New York, NY, USA, 1987.

50. Klotz, I.M. Physicochemical aspects of drug-protein interactions: General perspective. Acad. Sci. 1973, 226, 18-35. [CrossRef] [PubMed]

51. Uversky, V.N. Methods in Protein Structure and Stability Analysis: Conformational Stability, Size, Shape and Surface of Protein Molecules; Nova Publishers: New York, NY, USA, 2007.

52. van Holde, K.E.; Johnson, W.C.; Ho, P.S. Thermodynamics and biochemistry. In Principles of Physical Biochemistry, 2nd ed.; Prentice Hall: Upper Saddle River, NJ, USA, 2006; pp. 72-106. 